\title{
IS "LEARNING-BY-EXPORTING" \\ IMPORTANT? MICRO-DYNAMIC EVIDENCE \\ FROM COLOMBIA, MEXICO AND MOROCCO
}

\author{
Sofronis Clerides \\ Saul Lach \\ James Tybout
}

\author{
Working Paper 5715 \\ NATIONAL BUREAU OF ECONOMIC RESEARCH \\ 1050 Massachusetts Avenue \\ Cambridge, MA 02138 \\ August 1996
}

We thank Wolfgang Keller, Don Keesing, Yair Mundlak and Dani Rodrik for their comments, as well as seminar participants at Johns Hopkins University, UCLA, the University of Maryland, the World Bank, and the NBER Summer Institute (International Trade and Investment session). This paper was funded by the World Bank research project "Micro-foundations of Successful Export Promotion," RPO 679-20 and The World Bank's International Trade Division, International Economics Department. This paper is part of NBER's research program in International Trade and Investment. Any opinions expressed are those of the authors and not those of the World Bank, the Federal Reserve System, or the National Bureau of Economic Research.

(C) 1996 by Sofronis Clerides, Saul Lach, and James Tybout. All rights reserved. Short sections of text, not to exceed two paragraphs, may be quoted without explicit permission provided that full credit, including (C) notice, is given to the source. 


\title{
IS "LEARNING-BY-EXPORTING" \\ IMPORTANT? MICRO-DYNAMIC EVIDENCE \\ FROM COLOMBIA, MEXICO AND MOROCCO
}

\begin{abstract}
Is there any empirical evidence that firms become more efficient after becoming exporters? Do firms that become exporters generate positive spillovers for domestically-oriented producers? In this paper we analyze the causal links between exporting and productivity using firm-level panel data from three semi-industrialized countries. Representing export market participation and production costs as jointly dependent autoregressive processes, we look for evidence that firms' stochastic cost processes shift when they break into foreign markets. We find that relatively efficient firms become exporters, but firms' unit costs are not affected by previous export market participation. So the well-known efficiency gap between exporters and non-exporters is due to selfselection of the more efficient firms into the export market, rather than learning by exporting. Further, we find some evidence that exporters reduce the costs of breaking into foreign markets for domestically oriented producers, but they do not appear to help these producers become more efficient.
\end{abstract}

Sofronis Clerides

Department of Economics

Yale University

New Haven, CT 06520

\author{
Saul Lach \\ Board of Governors of the \\ Federal Reserve System \\ Stop 82 \\ 20th Street and Constitution Avenue, NW \\ Washington, DC 20551 \\ and NBER \\ m1sel00@frb.gov
}

James Tybout

Economics Department

Georgetown University

Washington, DC 20057-1045 


\section{Introduction}

Many analysts believe that export-led development strategies improve technical efficiency. And

one oft-cited reason is that exporters may benefit from the technical expertise of their buyers!

... a good deal of the information needed to augment basic capabilities has come from the buyers of exports who freely provided product designs and offered technical assistance to improve process technology in the context of their sourcing activities. Some part of the efficiency of export-led development must therefore be attributed to externalities derived from exporting." (Evenson and Westphal, 1995).

Buyers want low-cost, better-quality products from major suppliers. To obtain this, they transmit tacit and occasionally proprietary knowledge from their other, often OECDeconomy, suppliers. (World Bank, 1993, p. 320).

The important thing about foreign buyers, many of which have offices in Seoul, is that they do much more than buy and specify. .. They come in, too, with models and patterns for Korean engineers to follow, and they even go out to the production line to teach workers how to do things (Rhee, Ross-Larson, and Pursell, 1984, p. 41)

In support of this view, empirical studies often find that exporting plants are more efficient than their domestically oriented counterparts (Aw and Hwang, 1995; Bernard and Jensen, 1995, Chen and Tang, 1987; Haddad, 1993; Handoussa, Nishimizu and Page, 1986; Tybout and Westbrook, 1995; Roberts, Sullivan and Tybout, 1995). But, with the exception of Bernard and Jensen (1995) none of these studies has asked the question of whether exporting causes efficiency gains. Plausible arguments can be made for causality to flow in the opposite direction: relatively more efficient plants self-select into export markets because the returns to doing so are relatively high for them.

In this paper we attempt to sort out the direction of causality, and in so doing, determine whether there is evidence that firms learn to be more efficient by becoming exporters. Further, to assess the case for active export promotion, we test whether exporters generate external benefits for other firms, either by acting as a conduit for knowledge that they acquire through trade, or by causing improvements in

\footnotetext{
${ }^{1}$ For a recent catalog of additional reasons, see World Bank (1993, pp. 316-324).
} 
international transport and export support services. $^{2}$

Our methodology for detecting learning effects is based on a simple idea. If exporting indeed generates efficiency gains, then firms that begin to export should thereafter exhibit a change in the stochastic process that governs their productivity growth. Hence their productivity trajectories must improve in some sense after they enter foreign markets. Similarly, if the presence of exporters generates positive externalities, non-exporters in the affected industry or region should exhibit changes in their cost process when the number of exporters changes. Increases in the number of exporters may also make it easier for others to break into foreign markets.

To keep track of causal linkages we begin by specifying the general optimization problem that we envision firms as solving (section II). Each manager faces stochastic cost and foreign demand processes, and chooses which periods to participate in foreign markets. Their decisions are complicated by the presence of sunk start-up costs when they first sell abroad, since managers must research foreign demand and competition, establish marketing channels, and adjust their product characteristics and packaging to meet foreign tastes. The basic features of this model are taken directly from the hysteresis literature developed by Baldwin (1988), Dixit (1989), and Krugman (1989). Our twist is to add the possibility of learming-by-doing or, more precisely, learning-by-exporting, and examine how this affects the productivity trajectories of exporters and plants that switch markets, relative to those of non-exporters.

Because the framework we develop does not lend itself to closed-form solutions, we discuss its implications heuristically and using simulations. Under certain assumptions on the exogenous shocks to productivity and demand, the latter suggest that: (a) non-exporters experiencing positive productivity

\footnotetext{
${ }^{2}$ Many believe that these spillover effects are significant in developing countries. For example, Aitken, Hanson and Harrison (forthcoming) write that “ . . the development of garmet exporters in Bangledesh, suggests that informational externalities are likely to be extremely important. The entry of one Korean garment exporter in Bangladesh led to the establishment of hundreds of exporting enterprises, all owned by local entreprenuers. . Spillovers may take a variety of forms. The geographic concentration of exporters may make it feasible to construct specialized transportation infrastructure, such as storage facilities or rail lines, or may improve access to information about which goods are popular among foreign consumers."
} 
shocks self-select into foreign markets, (b) exporters experiencing negative productivity shocks quit foreign markets, and (c) the presence of learning-by-exporting effects implies that firms improve their relative productivity after they begin exporting.

With these results in hand, we examine the actual performance of Colombian, Mexican and Moroccan producers (section III). To familiarize ourselves with the data, we begin by comparing the productivity trajectories of producers that enter export markets with those of non-exporters, ongoing exporters, and firms that exit foreign markets. (Productivity is proxied by average variable cost and by labor productivity.) This exercise reveals patterns that our simulations suggest we should find in the absence of learning-by-exporting effects. That is, the plants that become exporters typically have high productivity before they enter foreign markets, and their relative efficiency does not systematically increase after foreign sales are initiated. In some instances the relatively strong performance of exporters traces to high labor productivity; in other instances it is due to relatively low costs of intermediate goods.

This first look at the actual trajectories casts doubt on the importance of learning-by-exporting. But it does not constitute a formal test of whether becoming an exporter changes a firm's productivity trajectory. Accordingly, in section IV we estimate econometrically a reduced-form version of the theoretical model which takes explicit account of the two alternative, but not incompatible, explanations for the positive association between export-participation status and productivity: self-selection of the relatively more efficient plants, and learning-by-exporting. For the countries with sufficient data to support inference--Colombia and Morocco--we find that export market participation generally depends upon past participation and (weakly) upon past average variable cost $(A V C)$, as implied by the model. However, conditioning on capital stock and past $A V C$ realizations, current $A V C$ does not depend negatively upon previous export market participation, as implied by the learning-by-exporting hypothesis. Thus, the conclusion suggested by our descriptive analysis is borne out by formal Granger causality 
tests. ${ }^{3}$ Finally, extending our model to look for externalities, we find some support for the hypothesis that

a firm is more likely to export if it belongs to an export-intensive industry or region, but we find little evidence of any associated productivity gains.

\section{A Model of Export Participation with Learning Effects}

Our first task is to present a model that specifies endogenous and exogenous sources of variation in the two producer characteristics we are interested in: exporting status and production costs. This model, which will guide us in our empirical analysis, is a simple modification of existing models to accomodate potential learning effects from export particiaption (Baldwin, 1989; Dixit, 1989; Krugman, 1989).

We begin by assuming monopolistic competition, so that each firm faces a downward sloping demand curve in the foreign market, yet views itself as too small to strategically influence the behavior of other producers. Specifically, we write foreign demand $q^{f}$ for the firm's product at price $p^{f}$ as $q^{f}=z^{f}\left(p^{f}\right)^{-\sigma^{f}}$, where the random variable $\mathrm{z}^{f}$ captures the usual demand shifters (foreign income level, exchange rates, and other goods' prices) and $\sigma^{f}>1 .{ }^{4}$ Firms face similar demand conditions in the domestic market, $q^{h}=z^{h}\left(p^{h}\right)^{-\sigma^{h}}$, and can price discriminate between foreign and domestic buyers.

Assuming constant marginal costs, $c$, the current period gross operating profits can be expressed as a function of marginal costs and demand conditions in both markets:

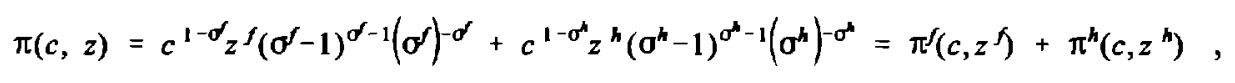

where $z=\left(z^{f}, z^{h}\right)$. The profits from exporting are the shaded area depicted in figure 1 below, where $p^{f}+p^{\prime}\left(q^{f}\right)$ and $p^{h}+p^{h '}\left(q^{h}\right)$ are foreign and home market marginal revenue, respectively. We represent the

${ }^{3}$ These conclusions are consistent with Bernard and Jensen's (1995) descriptive findings using U.S. data.

${ }^{4}$ This particular functional form for the demand function is generated by the Dixit-Stiglitz utility function over varieties. 
home demand curve as approaching the vertical axis above the foreign demand curve because transport costs and trade barriers eat up a fraction of each unit of revenue generated in foreign markets.

Figure 1: Gross Profits from Exporting

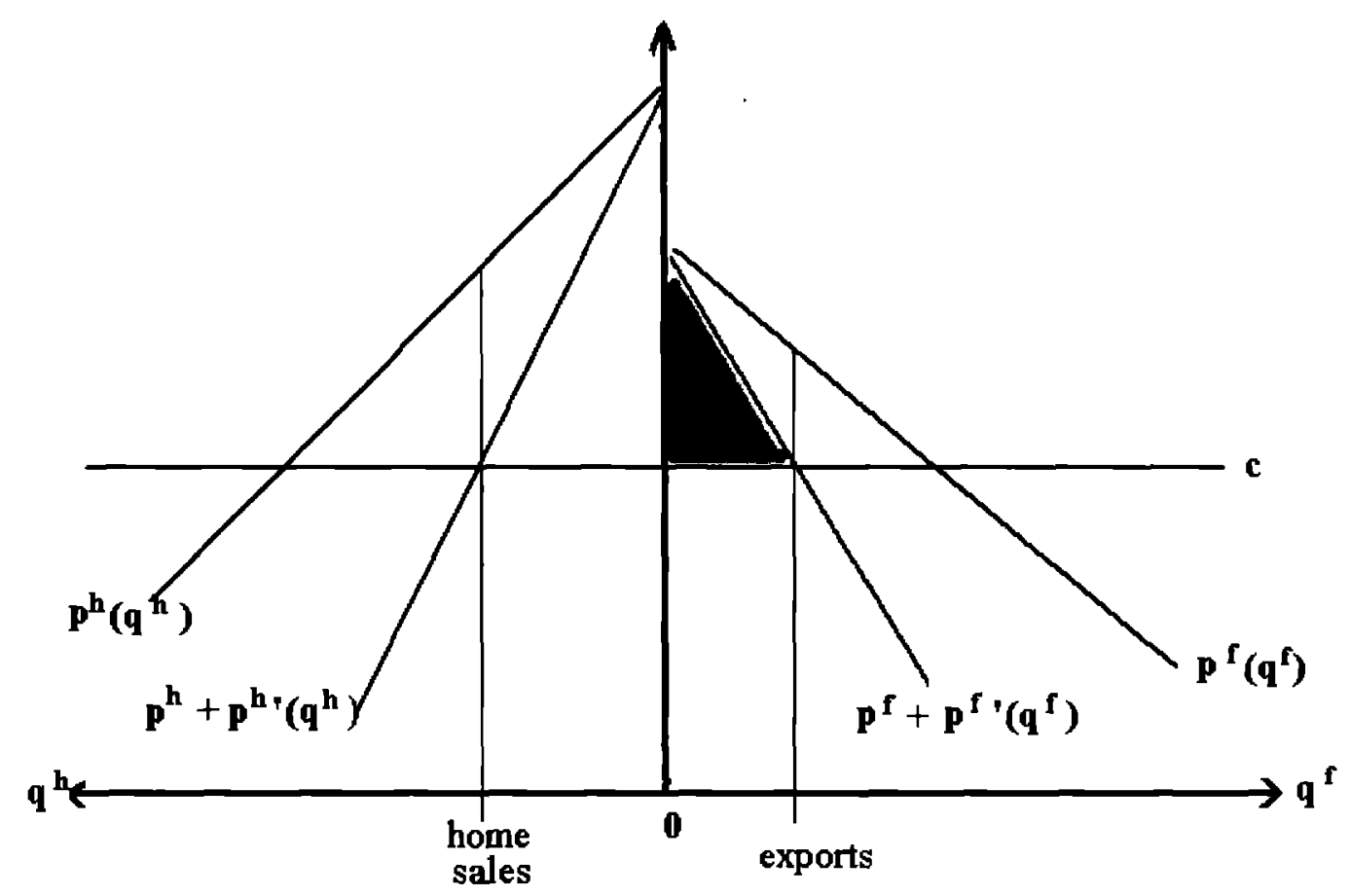

Let the per-period, fixed costs of being an exporter (e.g., dealing with customs and intermediaries) be $M$. Then, the plant will earn positive net operating profits from exporting whenever $\pi^{f}\left(c, z^{\mathcal{f}}\right)>M$. Accordingly, if there were no start-up costs associated with becoming an exporter and no learning effects, producers would simply participate in foreign markets--choosing the profit-maximing level of exports--whenever this condition was satisfied. As figure 1 demonstrates, given demand conditions, all firms with marginal costs below some threshold would self-select into export activities.

But as Baldwin (1989), Dixit (1989), and Krugman (1989) have recently stressed, sunk strart-up costs modify the problem in a non-trivial way. Suppose that an entry cost of $F$ dollars is incurred every time the plant decides to (re)start exporting. Then, once exporting, it may be optimal to keep exporting even if $\pi^{f}\left(c, z^{f}\right)$ is currently less than $M$ since, by remaining in the export market, the plant avoids future re-entry costs. So, if sunk costs are important--and micro evidence suggests that they are (e.g., Roberts 
and Tybout, 1995)--producers face a dynamic optimization problem where, in each period, they must choose whether or not to export on the basis of currently available information. This makes decisionmaking forward-looking and opens the possibility that firms export today in anticipation of cost reductions later. Hence, even if there are no learning-by-exporting effects, sunk start-up costs may imply that reductions in the marginal cost of production follow entry into foreign markets.

Because expectations are important in this context, we must be specific about the processes that generate the state variables $c$ and $z$. To account for heterogeneity in behavior we allow idiosyncratic, serially correlated shocks to demand and cost for each firm. We, therefore, assume that the demand shifter $z$ is exogenous to the plant, and follows some serially-correlated, plant-specific process (for simplicity, the plant-subscript is omitted until section IV):

$$
z_{1}=f\left(x_{t}, z_{i-1}^{1-\}}\right)
$$

where $x_{1}$ is a vector of exogenous variables that shift the demand processes, e.g., the exchange rate and plant-specific noise, and $\left.z_{t-1}^{t-1}=t_{t-1}, z_{t-2}, z_{t-3}, \ldots\right\}$ denotes the vector of previous realizations on $z_{t}$, up to and including period $t-1$.

Marginal cost also depends on its own history and, in addition, is potentially affected by the firm's exporting decisions if there are learning effects:

$$
c_{t}=g\left(w_{1}, c_{t-1}^{(-)}, Y_{t-1}^{(-)}\right)
$$

where $w_{r}$ is a vector of exogenous cost shifters, e.g., factor prices and plant-specific noise, and $Y_{t}^{(-)}=\left\{Y_{t}, Y_{t-1}, Y_{t-2}, \ldots\right\}$ denotes the history of the binary variable $Y$ which, in turn, indicates whether the plant was exporting j periods ago $\left(Y_{t, j}=1\right)$ or was not, $\left(Y_{t-j}=0\right)$. Note that we model learning-byexporting in a very specific manner: participation in the foreign market lowers marginal costs of production, irrespective of the volume of exports. If firms learn from other producers that export,

${ }^{5}$ This assumption simplifies the empirical analysis significantly because of the endogeneity of the level of exports. It also places fewer restrictions on the data. Note also that, for simplicity, the per-period fixed costs of 
variables that describe this external benefit should be included in the vector $w_{1}$.

A test for learning-by-exporting effects based on equation (3) must recognize that $Y_{t}$ is an endogenous variable, depending upon the same observed and unobserved factors that affect the cost and the demand processes. Thus, to sort out the relationship between $c$ and $Y$ we need to develop a representation of firms' exporting decisions. Following the hysteresis literature, we assume that managers take equations (1) through (3) into consideration, and plan their export market participation patterns to satisfy:

$$
V_{1}=\underset{Y_{t}^{l+}}{\max } E_{t}\left(\sum_{\tau=0}^{\infty} \delta^{\tau} Y_{t+\tau}\left(\pi^{f}\left(c_{t+\tau}, z_{t+\tau}^{f}\right)-M-\left(1-Y_{t+\tau-1}\right) F\right)+\sum_{\tau=0}^{\infty} \delta^{\tau} \pi^{h}\left(c_{t+\tau}, z_{t+\tau}^{h}\right)\right)
$$

Here $Y_{t}^{l+\}}=\left\{Y_{t}, Y_{t+1}, Y_{t+2}, \ldots\right\}$ denotes the entire future trajectory of $Y$ values, $E_{t}$ is an expectations operator conditioned on the set of information available at time $t$, and $\delta$ is the one-period discount rate ${ }^{6}$ Domestic profits enter this expression only because export market participation may affect the future cost trajectory. We assume that firms never wish to liquidate.

Equivalently, managers can be viewed as choosing the current $Y_{t}$ value that satisfies Bellman's equation:

$$
V_{t}=\max _{Y_{t}}\left[\left(\pi^{f}\left(c_{t}, z_{t}^{f}\right)-M-\left(1-Y_{t-1}\right) F\right) Y_{t}+\delta E_{t}\left(V_{t+1} \mid Y_{t}\right)\right]
$$

production are not affected by the export participation history.

${ }^{6}$ This formulation implies that producers who exit the export market and re-enter face the same start-up costs as producers who never exported. In our econometric rendering of the decision to export we will allow startup costs to depend upon previous exporting experience. 
This characterization of behavior implies that producers participate in export markets whenever

$$
\pi^{f}\left(c_{i}, z_{t}^{f}\right)-M+\delta\left[E_{t}\left(V_{t+1} \mid Y_{r}=1\right)-E_{t}\left(V_{r+1} \mid Y_{r}=0\right)\right] \geq F\left(1-Y_{t-1}\right)
$$

That is, incumbent exporters continue exporting whenever current net operating profits from exports plus the expected discounted future payoff from remaining an exporter is positive, and non-exporters begin exporting whenever this sum, net of start-up costs, is positive. Expected future pay-offs include the value of avoiding start-up costs next period and any positive learning effects that accrue from foreign market experience. Without learning effects, expression (6) has appeared in various forms in the hysteresis literature; it will prove useful in section IV.

If we allow for much generality in the cost process (3), and/or for the dependence of export profits on exporting history more than one period ago, it is very difficult to characterize optimal behavior in this framework. However, some insights can be gained by assuming that $c$ follows a discrete, firstorder Markov process that depends only on $Y_{t-1}{ }^{?}$ Then learning-by-exporting can be represented by assigning this term the transition matrix $\boldsymbol{P}_{\mathbf{0}}$ if the firm is not exporting, and some stocastically better matrix, say $\boldsymbol{P}_{1}$, if the firm is exporting. That is, among exporters the probability of a decrease in $c$ is greater, and the probability of a increase is less. The no-learning case simply assigns $\boldsymbol{P}_{0}$ to all firms. Simulations of cost trajectories based on this relatively restrictive framework and arbitrary parameter values are presented in figure 2. (Details are provided in appendix 1.) The trajectories are averages over repeated simulations for four subgroups of firms, labelled "non-exporters" (those that never export), "exporters" (those that always export), "entrants" (those that begin exporting), and "quitters" (those that cease exporting). For all firms that begin or cease exporting, we measure time

\footnotetext{
${ }^{7}$ Demand shifters can be held constant since their effect on profits is qualitatively the same as that of $c$.
} 
relative to the transition year (period 0 ), so for example, period -2 is two years prior to entry for the entrant group, and two years prior to exit for the quitter group. Firms that export may or may not be subject to learning effects.

Figure 2a: Entrants and Quitters

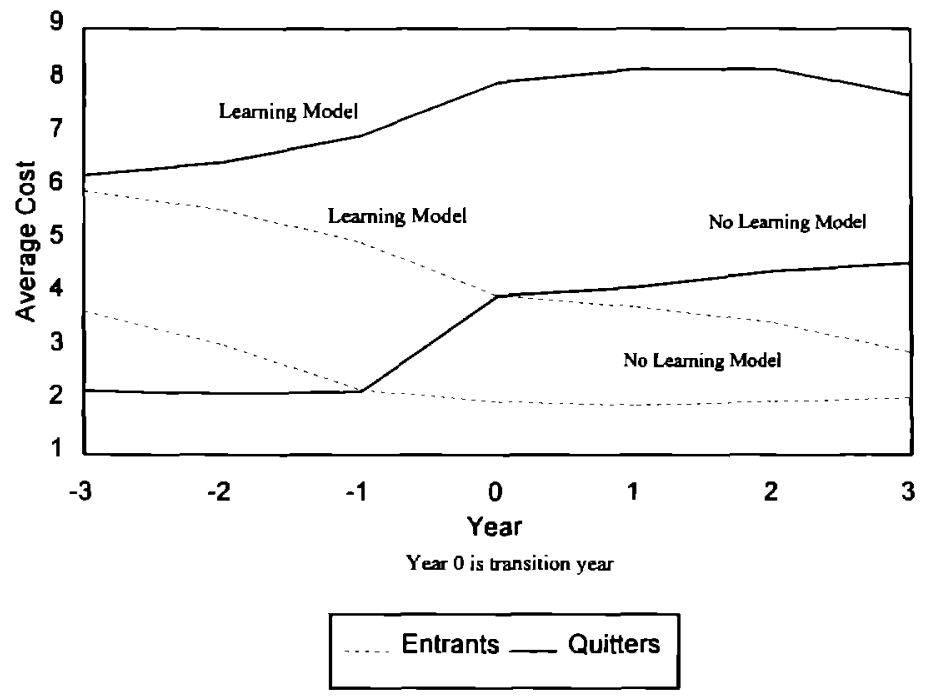

Figure 2b: Exporters and Non-exporters

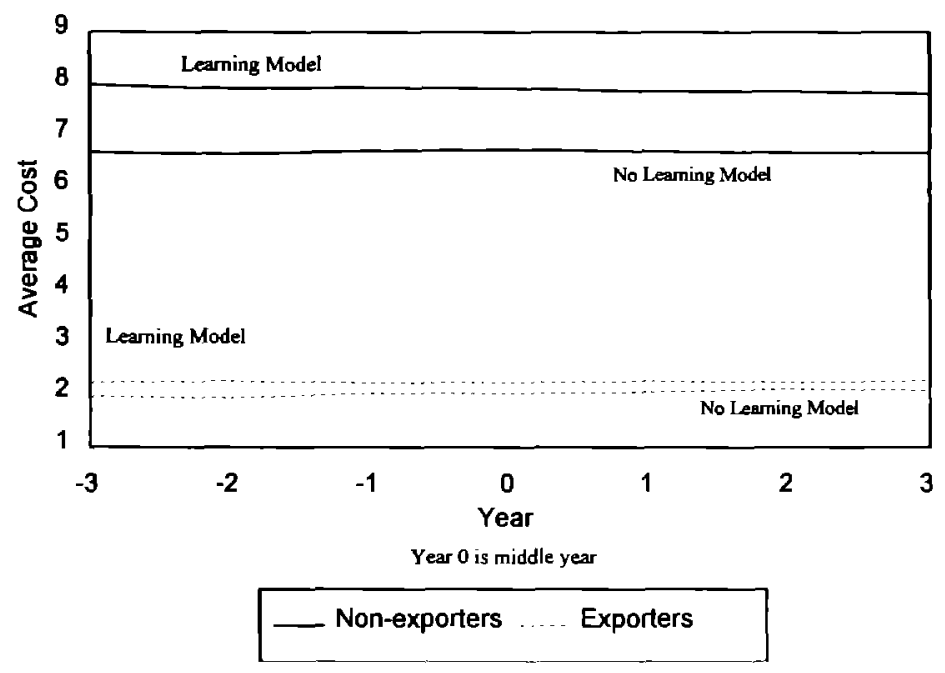

Several patterns merit note. First and most obviously, regardless of whether leaming effects are present, costs among the entrant and the exporter firms are lower than costs in the other two groups. This reflects 
the self-selection of efficient firms into export markets, and demonstrates why we cannot rely on static cost comparisons between exporters and non-exporters to make inferences about learning.

Second, regardless of whether learning effects are present, firms that become exporters exhibit cost declines before they enter the market. These firms self-select into exporting only when their unit costs fall below some threshold, so they must experience a period of falling costs prior to entry. Hence selection effects may create the illustion that becoming an exporter actually retards productivity growth.

Third, one distinguishing feature of the learning trajectories is that exporting firms exhibit ongoing cost reductions after initiating foreign sales. Only when learning effects are present, do firms continue to pull away from non-exporters after foreign market entry.

Finally, relative to the no learning case, learning makes firms enter (and stay in) export markets at higher costs. This occurs because the incentives to export are larger when learning occurs. Productivity dispersion may thus be higher among exporters when learning effects are present, and the productivity gap between exporters and non-exporters may be smaller. ${ }^{8}$

Of course, these results are only suggestive, and more complicated cost processes might reverse some of the patterns. For example, if costs were to follow a second- or higher-order autogressive process, they might continue to trend downward after export market entry even without learning effects.

Accordingly, to look for learning effects and externalities, we rely on econometric estimates of a general form of the cost function (3), recognizing that export market participation is governed by the behavioral rule (6).

\section{Learning Effects: A Look at Actual Data}

Before we report the results of that exercise, however, it is instructive to visually examine cost data on actual producers from three semi-industrialized countries. Though merely suggestive, this will

\footnotetext{
${ }^{B}$ More generally, this result suggests caution interpreting studies that use productivity dispersion as a performance measure. (See especially the "efficiency frontier" literature). When learning effects are present, exporters may look relatively bad.
} 
familiarize the reader with the basic patterns we are trying to explain, and provide an informal check for the distinguishing patterns that our simulations suggest we should find when learning effects are present.

\section{A. The Data}

Our data allow us to follow individual producers through time in Colombia, Mexico and Morocco. In the case of Colombia, they describe virtually all plants with at least 10 workers over the period 1981-1991; in Mexico, they describe 2800 of the larger firms over the period 1986-1990, and in Morocco they cover most all firms with at least 10 workers over the period 1984-1991? Standard information on inputs, outputs and costs is provided in each of these data bases, as well as information on export levels. To simplify estimation we throw out firms that do not report information for the entire sample period, creating a balanced panel. The data were cleaned and deflated as described in Appendix II.

Finally, to sharpen the analysis, we focus only on the export-oriented industries in each country. These industries exported at least 10 percent of their output, and had at least 20 exporting plants. ${ }^{10}$ Table 1 provides descriptive information on each country. Note that although most plants tend to stay in the export market or stay out, there are substantial transitions in the data.

\footnotetext{
${ }^{9}$ Although some countries report plant-level data and some report firm-level data, we will hereafter use the term "plant" to describe the unit of observation. In semi-industrialized countries where the calculation is possible, we have found that 95 percent of the plants are owned by single-plant firms.

${ }^{10}$ In a few cases, industries that exported less than 10 percent of their output were included because they hand many exporting plants and/or accounted for a substantial share of total manufactured exports.
} 
Table 1: Entry, Exit, Number of Plants and Export Intensity by Country

(Export-oriented Industries)

\begin{tabular}{||ccccc||}
\hline & $\begin{array}{c}\text { Ave. Annual } \\
\text { Entry Rate }\end{array}$ & $\begin{array}{c}\text { Ave. Annual } \\
\text { Exit Rate }\end{array}$ & $\begin{array}{c}\text { Ave. Number of } \\
\text { Plants }\end{array}$ & $\begin{array}{c}\text { Average Export } \\
\text { Intensity }\end{array}$ \\
\hline $\begin{array}{c}\text { Colombia } \\
1981-1991\end{array}$ & .027 & .017 & 1,354 & .095 \\
$\begin{array}{c}\text { Morocco } \\
\text { 1984-1991 }\end{array}$ & .049 & .037 & 938 & .360 \\
$\begin{array}{c}\text { Mexico, } \\
1986-1990\end{array}$ & .048 & .015 & 1,327 & .230 \\
\hline
\end{tabular}

\section{B. Comparing Productivity Trajectories}

We wish to familiarize ourselves with the marginal cost trajectories of plants with different export market participation patterns, controlling for industry-wide time effects, and observable plantspecific productivity determinants like capital stocks and age. We use two marginal cost proxies: average variable cost $(A V C)$ and labor productivity $(L A B)$. The former is defined as the sum of labor and intermediate input costs divided by real output, and the latter is real output divided by number of workers. Real output is the sum of nominal output for the domestic market and nominal output for export, each deflated by its own product-specific deflator.

To purge these productivity measures of industry-wide time effects and observable plant-specific characteristics, each is expressed in logarithms and regressed on time dummies (specific to year $t$ and the $j^{\text {th }}$ 3-digit ISIC industry), age of the plant (A), age of the plant squared, capital stock of the plant (K), and capital stock of the plant squared. Both age and capital stocks are measured in logarithms:

$$
\begin{aligned}
& \ln \left(A V C_{i t}\right)=\sum_{j=1}^{J} \sum_{i=1}^{T} \gamma_{j t} D_{j t}+\beta_{1} \ln \left(A_{i t}\right)+\beta_{2} \ln \left(A_{i t}\right)^{2}+\beta_{3} \ln \left(K_{i t}\right)+\beta_{4} \ln \left(K_{i t}\right)^{2}+\epsilon_{i t} \\
& \ln \left(L A B_{i t}\right)=\sum_{j=1}^{J} \sum_{i=1}^{T} \gamma_{j t}^{L} D_{j t}+\beta_{1}^{L} \ln \left(A_{i t}\right)+\beta_{2}^{L} \ln \left(A_{i t}\right)^{2}+\beta_{3}^{L} \ln \left(K_{i t}\right)+\beta_{4}^{L} \ln \left(K_{i t}\right)^{2}+\epsilon_{i t}^{L}
\end{aligned}
$$


The residuals from these two regressions are then used as our indices of deviation from time- and industry-specific productivity norms. Note that there is no need to deflate variable costs directly because industry-specific time dummies play the role of price deflators (inter alia). Also, because logarithmic variable costs are purged of correlation with capital, the residuals can be viewed as the measure of variable factor productivity that obtains from a total cost function of the form

$C_{i t}=\lambda_{0}\left(K_{i r}, W_{i t}\right)+\lambda_{1}\left(K_{i r}, W_{i t}\right) Q_{i t}$, where parentheses denote functions, $K_{i t}$ is capital, and $W_{i t}$ is the vector of factor prices.

To isolate the relation between export market participation and productivity performance, we distinguish the five varieties of plants defined in Table 2, and for each plant we re-define period zero to be the year in which a change in export status takes place. Then we isolate five-year blocks of time, running from two years prior to the status change $(t=-2)$ to two years after $(t=2) !^{1} \quad$ For non-exporters and exporters there is no change in status, so we take five years in the middle of the sample period (for Colombia we take seven years). Finally, after re-indexing time in this way, we aggregate our productivity indices by plant type and compare them. Because switching firms strongly resemble exporters we omit them from our graphs to reduce clutter.

\section{Table 2: Firm Varieties}

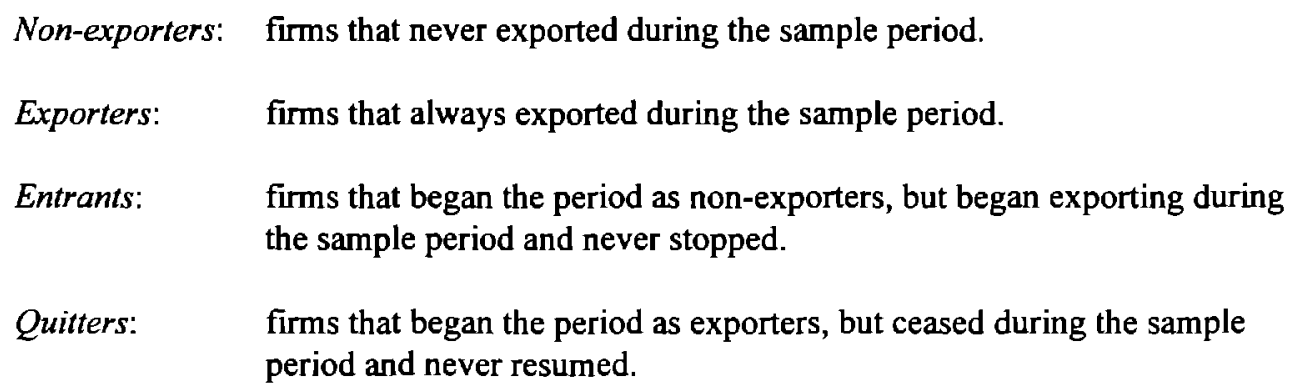

Switchers: firms that switched exporting status more than once during the sample period. switch.

"The Colombian panel is long enough to allow us to go from three years prior to three years after the 


\section{Basic Trajectory Patterns}

Average Variable Costs: Unweighted average trajectories for average variable costs are presented by plant type in Figures 3.1 through 3.3. We begin by considering Colombia and Mexico, since these countries show similar patterns. Most strikingly, plants that cease exporting get steadily worse before they drop out of foreign markets, and are substantially less efficient than the other plant types. Also, entering plants and exporting plants share the distinction of having the lowest variable costs, and nonexporters consistently exhibit costs slightly above average, but less than quitters. These patterns are similar to the simulations in figure 1 for both the learning and non-learning models, except in that the performance of quitting plants is somewhat worse in the actual data.

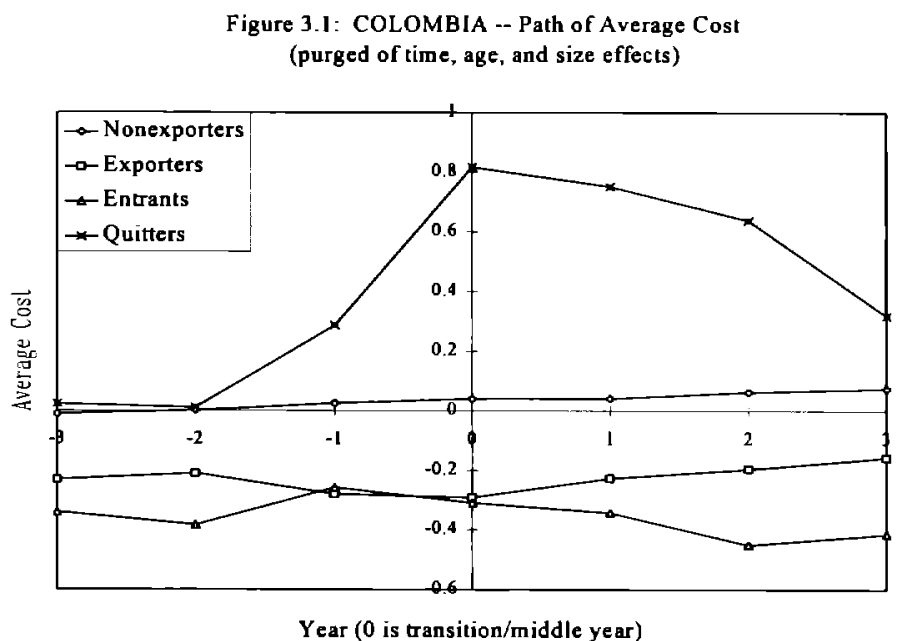

Figure 3.2: MEXICO -- Path of Average Variable Cost (purged of time and size effects)

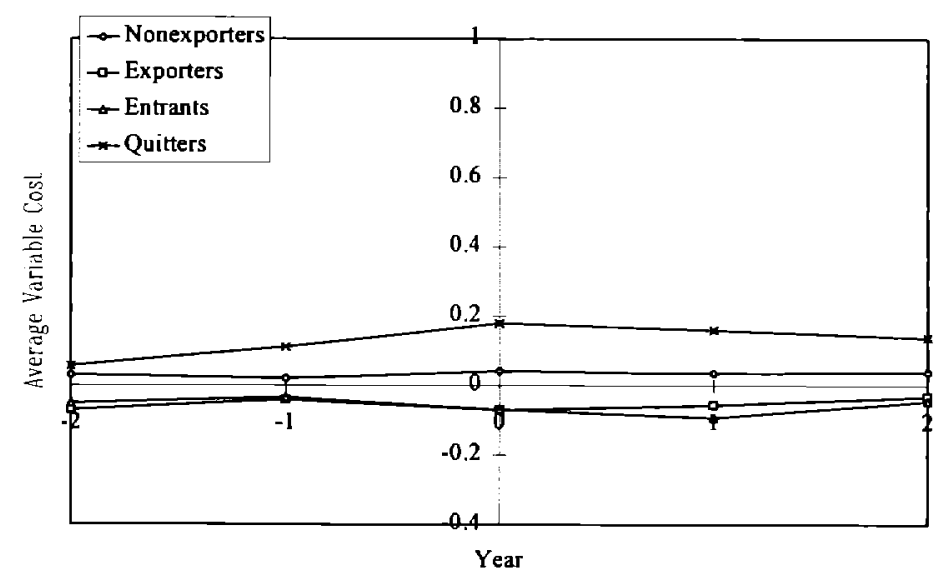


One might argue about whether the entrants show evidence of reducing their costs after beginning to export, but the effect is certainly not dramatic. The F-statistic for the null hypothesis that the mean average cost level among entrants shows no variation relative to the industry norms has a p-value of .08 in Colombia, and a p-value of .25 in Mexico. ${ }^{12}$ Further, in Mexico, entrants' average costs are slightly higher relative to industry norms after three years of exporting than they were three years before.

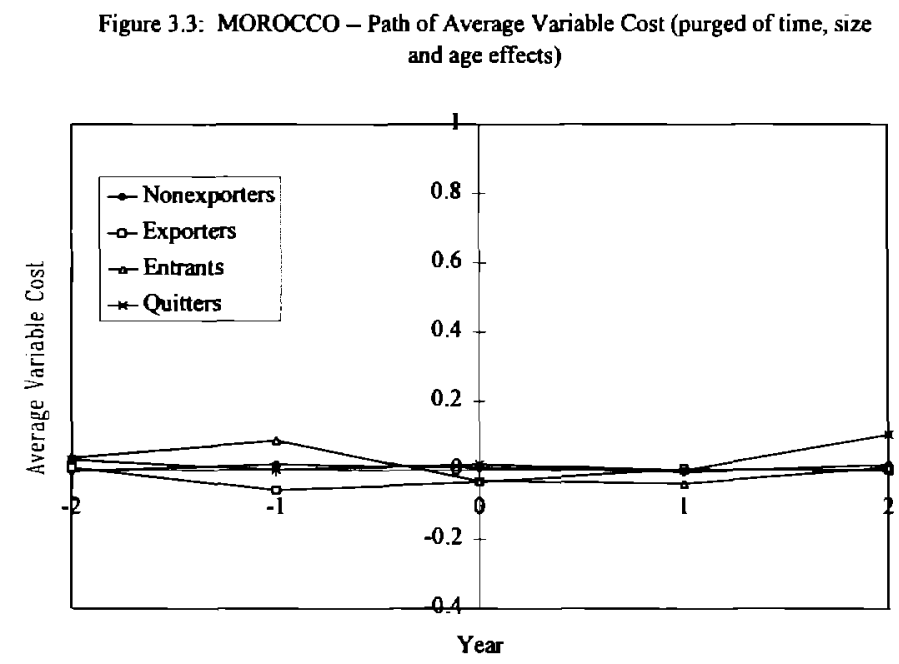

The Moroccan graph is more complex. Most obviously, there is much less variation in trajectories here than we found in Colombia and Mexico. Further, what little variation there is does not conform to the patterns described above. Two years after exiting, the plants that abandon foreign markets emerge as the worst plants, but their average variable costs are highly volatile, and no higher than the industry norm one year after exiting. Exporters usually do better than non-exporters, but even this is not guaranteed.

These patterns may well reflect the fact that, unlike in Mexico and Colombia, most of the impetus to become an exporter in Morocco came from firm-specifc demand side shocks. Many Moroccan exporters are young plants that were founded with the exclusive purpose of selling particular apparel and

${ }^{12}$ These tests are based on generalizations of the regression model to include annual dummies by plant type. We also allow the coefficients on age, age squared, capital and capital squared to vary across indsutry, and we treat the disturbance as composed of a fixed plant effect plus random noise. 
textile products abroad (Sullivan, 1995; World Bank 1994; Roberts, Sullivan, Tybout, 1995). Moroccan

policies during the sample period also provided various subsidies to exporters, and these may have allowed less efficient plants to compete. Once again there is little statistical evidence that average costs among plants that begin exporting are anything but flat relative to industry norms (the p-value is .24).

The results discussed thus far are based on unweighted averages of our variable cost measures. But small plants are much more common than large plants, so Figures 3.1 through 3.3 do not necessarily describe sector-wide performance. To determine whether aggregate performances looked similar, we therefore redid the calculations, weighting each plant's average cost by its share in the total output among those of its type. We also redid the plant-specific average cost measures themselves, leaving capital stocks and age out of the regression, because we did not want them to be purged of correlation with size for this exercise.

The weighted average cost trajectories by plant type are presented in Figures 4.1 through 4.3 . For Colombia the pattern looks very similar, except that exporters' costs are no longer below those of non-exporters. So small exporters are apparently more efficient than large exporters in terms of variable costs. In Mexico the pattern is also similar, except exporters' costs now turn up dramatically in the last period. This is presumably because of one or several very large plants. Finally, it remains true that entrants exhibit relatively low average costs, both before and after the transition year. There is no obvious tendency for costs to fall after exporting operations are initiated.

In Morocco, the weighted average trajectories are as flat and tightly clustered as their unweighted counterparts. As with the other countries, there is no evidence that costs drop after exports are initiated. However, the weighted figures do provide better support for the assertion that exporters tend to be lower cost than non-exporters. 
Figure 4. 1: COLOMBLA -- Path of Output-Weighted Average Cost (purged of time effects only)

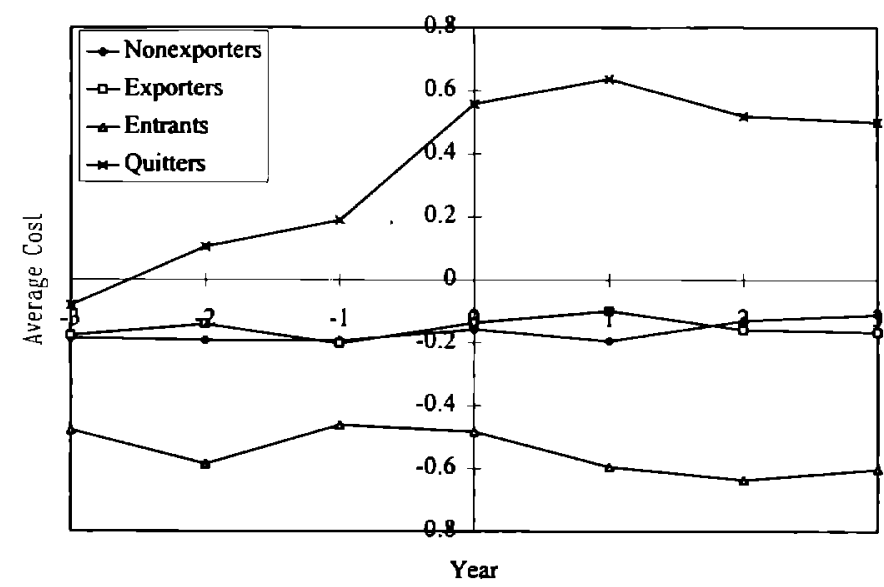

Figure 4.2: MEXICO - Path of Output-Weighted Average Variable Cost (purged of time effects only)

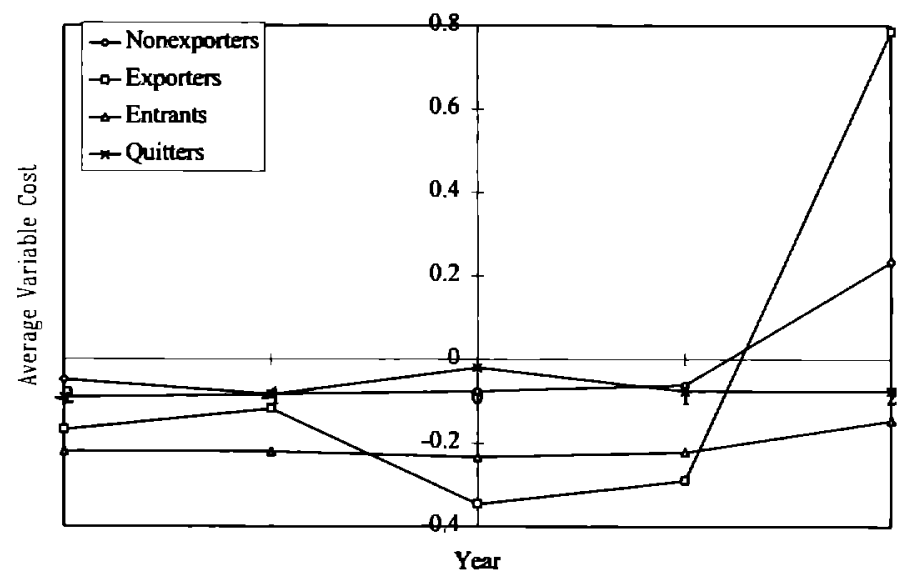




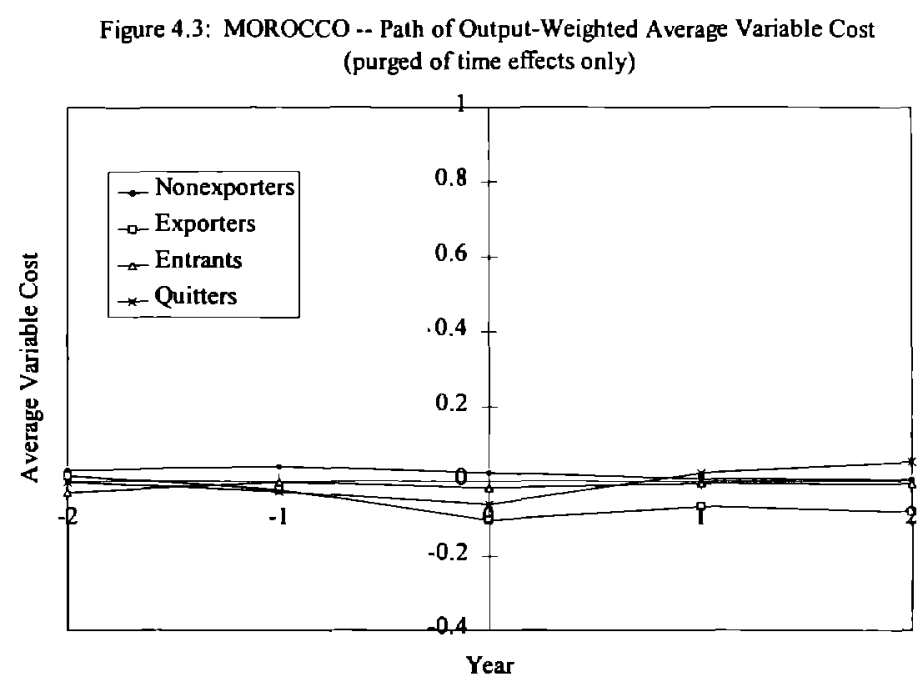

Labor productivity: An alternative measure of performance is output per worker. Unlike costs, it does not reflect valuation effects due to changes in factor prices, as might happen if exporters began using imported inputs under a duty drawback scheme, or if real exchange rate fluctuations affected producers to the extent that they used imported intermediates. Like average variable costs, labor productivity is not a true measure of total factor productivity, but after it has been purged of correlation with capital stocks it is conceptually closer.

Figure 5.1: COLOMBLA - Path of Average Labor Productivity (purged of time, age, and size effects)

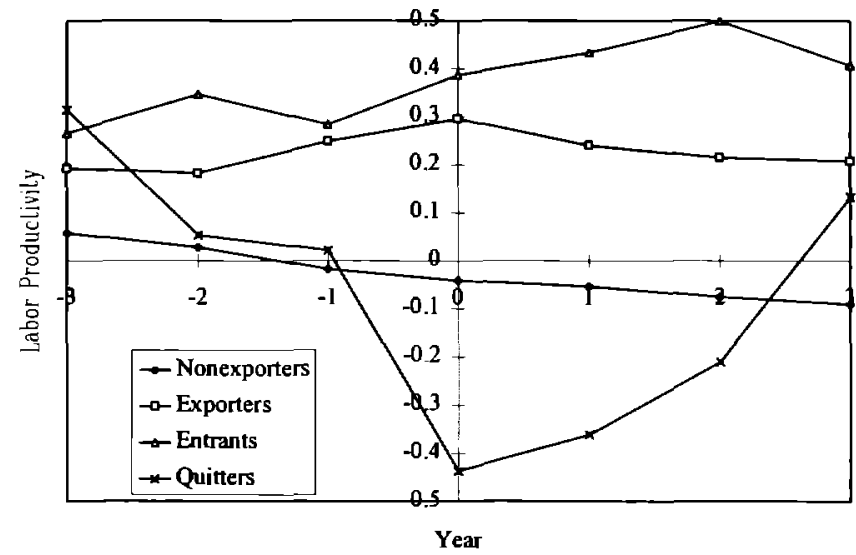

Figure 5.1 presents unweighted average values of this productivity measure by plant type for 
Colombia, The entrants once again perform the best, and in contrast to their average cost patterns

(Figures 3.1 and 4.1 ) do seem to improve when they initiate foreign sales. ${ }^{13}$ Ongoing exporters continue to show the next best performance, and quitters continue to show the worst performance, particularly around the time of their exit. So in Colombia, it appears that output per worker is one important source of variation in average variable costs, and we have the first bit of evidence that exporting might improve performance.

Quitters and ongoing exporters in Mexico follow the Colombian pattern. But Mexican entrants do not. Their average labor productivity is very stable relative to industry norms ( $p$-value $=.61$ ), and a bit below average (Figure 5.2). So there is no suggestion of a learning effect from exporting in this country, nor, for that matter, does it appear that cross-plant exporting patterns can be traced to differences in labor productivity.

Figure 5.2: MEXICO - Pahth of Average Labor Productivity (purged of time and size effects)

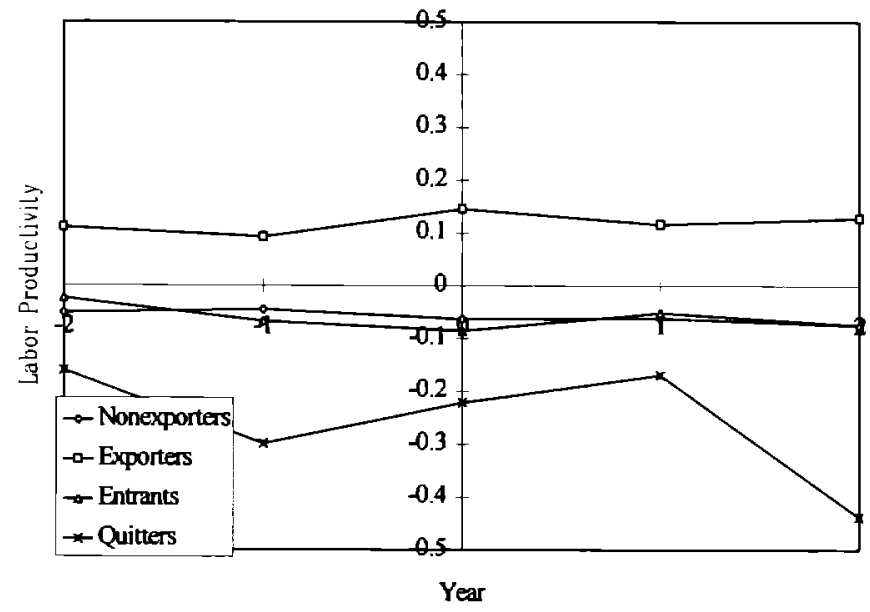

13 The F-statistic for the null hypothesis that average labor productivity among these plants doesn't change relative to industry norms has a $p$-value of, 01 . See also footnote 11 . 
Figure 5.3: MOROCCO - Path of Labor Productivity (purged of time, size, and age effects)

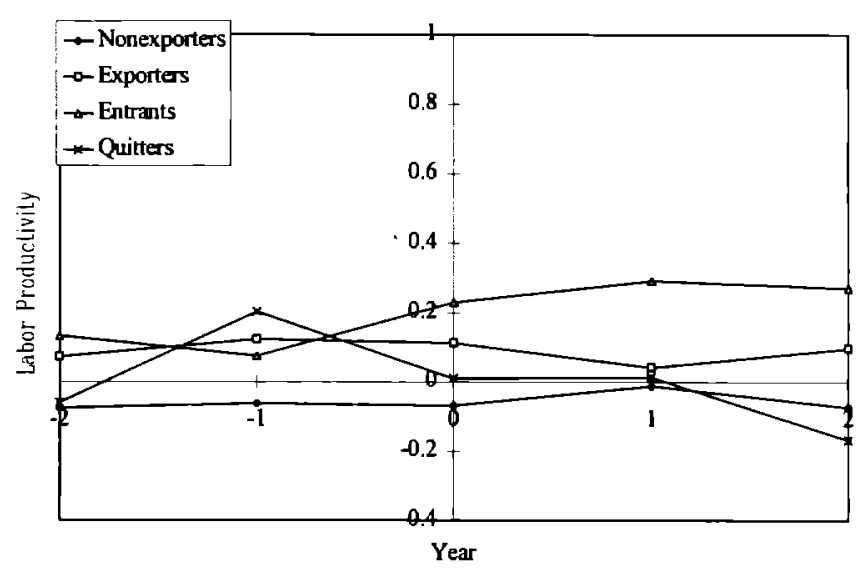

Finally, in terms of labor productivity, Moroccan patterns appear to resemble Colombia's (Figure 5.3). Entrants' productivity jumps in the year that they begin exporting (although the $p$-value is .41 ), and ongoing exporters exhibit higher labor productivity than either non-exporters or quitters..$^{14}$ Interestingly, there is much more variation across plant types in our Moroccan labor productivity series than we found in our average cost series, suggesting that labor costs co-vary negatively with intermediate goods costs in this country.

Weighting our labor productivity series by plant size gives a better picture of aggregate performance for each of the plant types. We report the results of this exercise in Figures 6.1 through 6.3, using series that have not been purged of correlation with capital stocks or age. In Colombia, the pattern for entrants and quitters seems largely unchanged from Figure 5.1, although there is no longer any recovery in labor productivity among the latter in the years after they exit. Also, ongoing exporters no longer consistently outperform non-exporters, suggesting that this was mainly a small plant phenomenon. These are the same contrasts we identified with our weighted versus unweighted average cost series. markets.

\footnotetext{
${ }^{14}$ The one exception is that labor productivity is high for exiting plants during their last year in foregin
} 
Figure 6.1: COLOMBIA -- Path of Output-Weighted Labor Productivity (purged of time effects only)

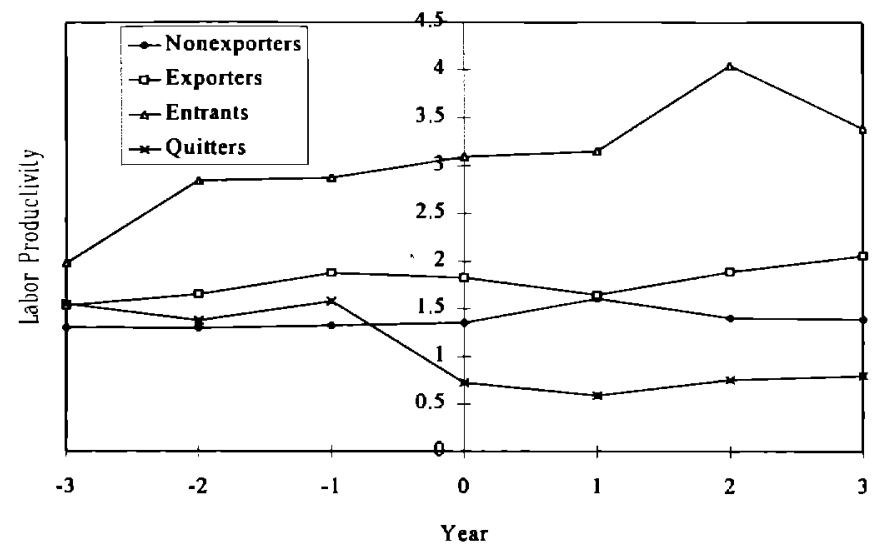

Figure 6.2: MEXICO -- Path of Output-Weighted Labor Productivity (purged of time effects only)

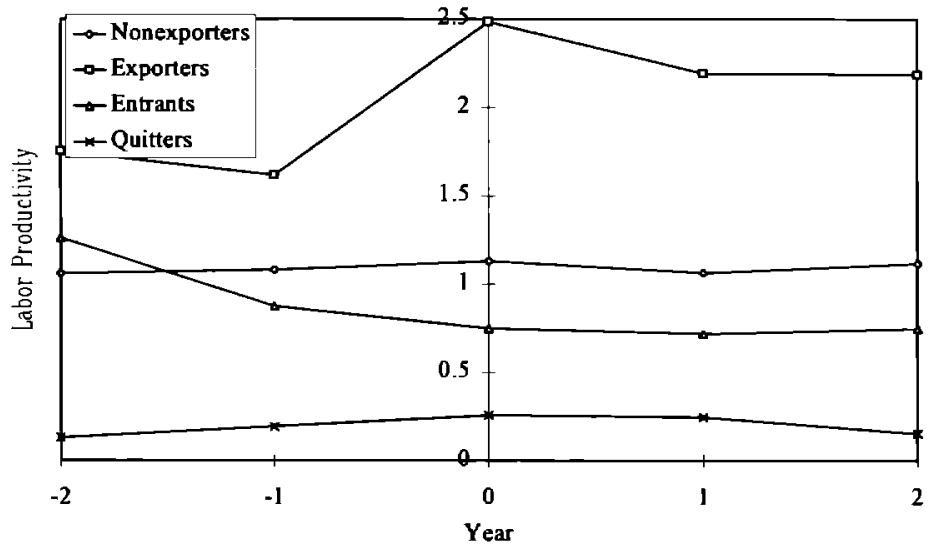




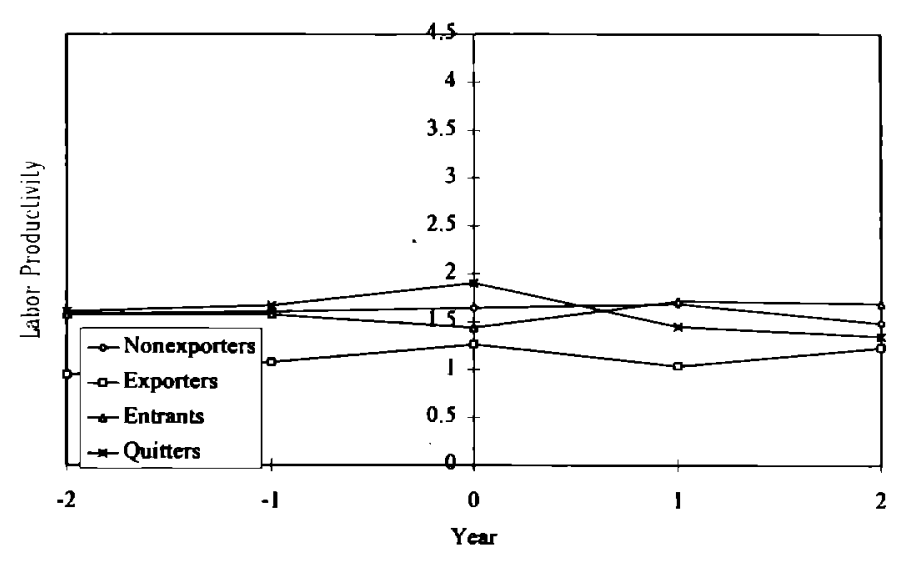

The Mexican trajectories do not seem to depend much upon whether we use weighted or unweighted labor productivity, although quitters' performance is more stable with the former (Figure 6.2). On the other hand, in Morocco our use of a weighted series (Figure 6.3) undoes much of what emerged in the unweighted series. (Figure 5.3). Exporters become the least productive when we weight by size, and the tendency for entrants to improve after they begin exporting is dampened. These results, in conjuction with the low power of test statistics for our unweighted trajectories, suggest that the unweighted series reflect the influence of small plants that are outliers.

Labor Quality: One fundamental source of variation in labor productivity is associated variation in the skill mix of employees. To see whether differences in skill mixes are behind the labor productivity differences we analyzed the ratio of skilled to total labor in the same way we analyzed our two productivity series. ${ }^{15}$ The results for Colombia are presented in Figure 7.1. Interestingly, entrants appear to have high labor productivity partly because they use skilled labor relatively intensively, and quitters have low productivity because they use little skilled labor. There is also some evidence that relative labor quality improves over time for the entrants (the $p$-value is .09 ). The high labor productivity of ongoing exporters does not, however, appear to come from unusually high skill intensity. None of these patterns

15 No results are presented for Morocco because of lack of appropriate data. 
is sensitive to whether we use weighted or unweighted skill intensity series so we report only the latter. One interpretation is that breaking into foreign markets requires new product design and other forms of technical assistance, but established export production can be routinized.

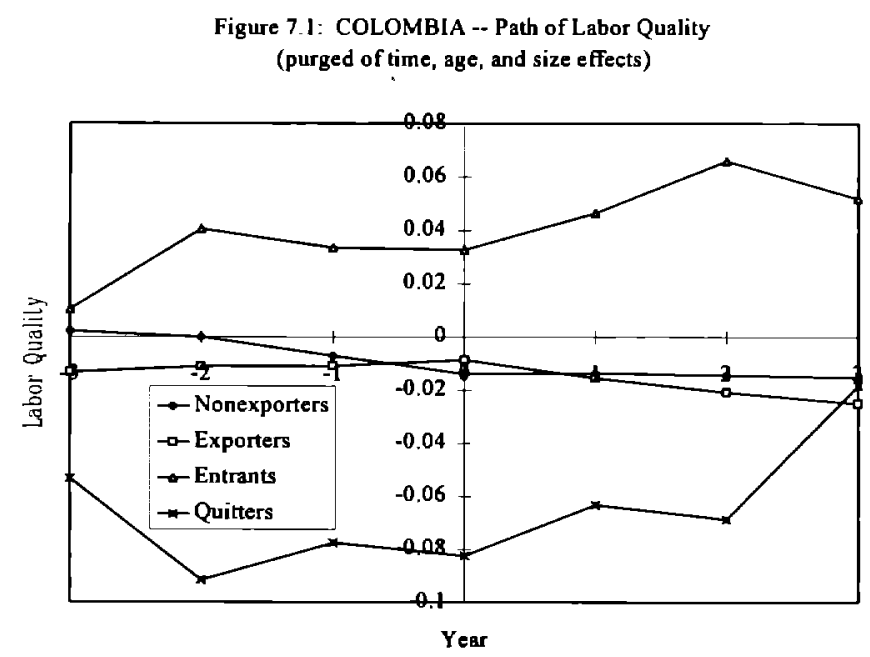

In Mexico, labor quality trajectories match labor productivity trajectories for ongoing exporting plants (which are skill-intensive) and exiting plants (which are not). However, although Mexican entrants resemble Colombian entrants in terms of skill intensity, this is not sufficient to get them high labor productivity (Figure 7.2 versus Figure 5.2). The Mexican results are somewhat sensitive to weighting; when this is done non-exporters actually exceed exporters in terms of skill intensity. Nonetheless, entrants remain above average, and quitters are well below average. 


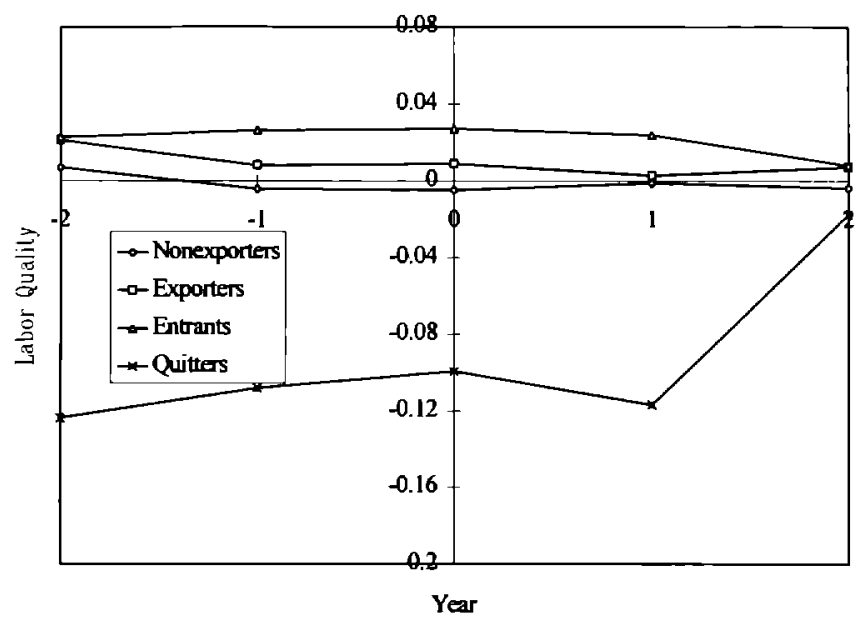

In summary, our performance measures indicate that entrants generally do better than nonexporters and exiting plants. They have higher labor producivity, and this appears to be partly due to their heavier reliance on skilled labor. Also, despite their high quality workers, new exporters have relatively low average variable costs. On the other hand, we find little to suggest that productivity gains follow entry into foreign markets. Labor productivity and skill-intensity appear to improve for Colombian plants that begin exporting, but this phenomenon did not show up in the other countries. Interestingly, Bernard and Jensen (1995) have recently reported that many of these patterns are evident among U.S. manufacturers as well.

\section{An Econometric Test of Learning Effects}

The figures we report in the previous section are revealing, but they do not consitute a direct test for whether past export market participation influences current costs; the F-statistics we calculated merely indicate whether cost trajectories for entering firms deviate significantly from industry norms. Hence in this section we develop an alternative approach to test for the presence of learning-by-exporting effects in the data. Specifically, we estimate a fairly general version of equations (3) jointly with a reduced form of 
(6), and test whether exporting history, $\quad \boldsymbol{Y}_{u}^{(-)}$, enters significantly in the cost equation. ${ }^{16}$ In other words, we perform Granger causality tests in a non-linear context.

\section{A. The Econometric Model}

Our treatment of the export market participation decision follows Roberts and Tybout (1995).

First, we generalize equation (6) so that firms which exit and re-enter the export market pay different start-up costs than firms that never exported. Specifically, defne $F^{a}$ as the start-up cost for a nonexporter with no previous experience, and $F^{j}$ as the start-up cost faced by a firm that last exported $j-1$ years ago (note that $F^{1}=0$ ). Then equation (6) generalizes to imply that the $t^{h}$ firm will export in year $\mathrm{t}$ (i.e., will choose $Y_{1}=1$ ) whenever

$$
\pi^{f}\left(c_{i t}, z_{i t}^{f}\right)-M+\delta\left[E_{t}\left(V_{i t+1} \mid Y_{i t}=1\right)-E_{i}\left(V_{i t+1} \mid Y_{i t}=0\right)\right] \geq F^{0}-\sum_{j=1}^{J}\left(F^{0}-F^{j}\right) \tilde{Y}_{i t-j},
$$

where $\tilde{Y}_{i t-j}$ is one if the firm last exported in year $t-j$ and zero otherwise. ${ }^{17}$ Next, we define the latent variable $Y^{*}$ as current net operating profits plus the expected future return to being an exporter in period $t$ :

$$
Y_{i r}^{*}=\pi^{f}\left(c_{i r}, z_{i t}^{5}\right)-M+\delta\left[E_{t}\left(V_{i t+1} \mid Y_{i r}=1\right)-E_{t}\left(V_{i r+1} \mid Y_{i r}=0\right)\right]
$$

Equation (7) then implies that $Y_{i t}$ obeys the following dynamic discrete process:

16 If we allow for much generality in the processes (2) and (3), it becomes very difficult to estimate all the structural parameters of the model. Yet imposing restrictions on these processes may well lead us to incorrectly conclude that past participation in the export market influences current marginal costs. For example, misspecifying equations (2) and (3) to be first-order processes may force any dependence of current costs on additional lags (e.g., $\left.c_{t-2}, c_{t-3}\right)$ to come through $Y_{t-1}$, giving the impression that export market participation affects costs. Thus, if the goal is to look for learning effects, it is desirable to pursue a reduced-form approach.

17 Note that $\tilde{Y}_{i t-1}=Y_{i t-1}$ and, for $\rho>2, \quad \tilde{Y}_{i t-j}=Y_{i t-j} \prod_{k=1}^{j-1}\left(1-Y_{i t-k}\right)$. 


$$
Y_{i t}=\left\{\begin{array}{l}
1 \text { if } Y_{i t}^{*} \geq F^{0}-\sum_{j=1}^{J}\left(F^{0}-F^{j}\right) \tilde{Y}_{i r-j} \\
0 \text { otherwise }
\end{array}\right.
$$

Finally, we express the latent variable $Y_{i r}^{*}-F^{0}$ as a reduced form in demand shifters, marginal costs, as well as the variables that help predict future marginal costs and demand in each market. ${ }^{18}$ Operationally, this means including exogenous plant characteristics $\left(X_{i t}\right)$, time dummies $\left(D_{t}\right)$, a distributed lag in our marginal cost proxy, $A V C_{i t}$, and a serially correlated disturbance. Writing startup costs at the $i^{\text {th }}$ plant as their mean value plus another disturbance, we have:

$$
\begin{aligned}
& Y_{i t}^{*}-F_{i t}^{0}=\beta^{\mathrm{x}} X_{i t}+\sum_{\tau=1}^{\mathrm{T}} \beta_{\tau}^{d} D_{i}^{\tau}+\sum_{j=1}^{J} \beta_{j}^{c} \ln \left(A V C_{i t-j}\right)+\xi_{i t}^{Y} \\
& F_{i t}^{j}=F^{j}+\xi_{i t}^{F}
\end{aligned}
$$

Then substituting (9a) and (9b) into (8) we obtain a representation of export market participation decisions that can be estimated:

$$
Y_{i t}=\left\{\begin{array}{l}
1 \text { if } 0 \leq \beta^{z} Z_{i t}+\sum_{\tau=1}^{T} \beta_{\tau}^{d} D_{t}^{\tau}+\sum_{j=1}^{J} \beta_{j}^{c} \ln \left(A V C_{i r-j}\right)+\sum_{j=1}^{J} \vec{Y}_{i t-j}\left(F^{0}-F^{j}\right)+\eta_{i t} \\
0 \quad \text { otherwise }
\end{array}\right.
$$

where $\eta_{i t}$ is a serially correlated compound disturbance based on the errors in equation (9).

Notice that the estimated coefficients on our lagged participation variables measure the discount on entry costs that plants with exporting experience in previous years enjoy, relative to plants with no exporting experience. For example, a plant that most recently exported $j-1$ years ago pays only $F^{0}-F^{\prime}$ to resume exporting operations, while a plant that never exported pays start-up costs

18 This reduced form approach is also used in Sullivan (1995) and Roberts, Sullivan and Tybout (1995). 
$F^{0}$. Further discussion may be found in Roberts and Tybout (1995).

As noted in section II, if firms learn by exporting the stochastic process that generates costs also depends upon the history of $Y_{i s}$ values. Accordingly, a general log-linearized specification of the marginal cost function (3) includes not only capital stocks, lagged cost, and factor prices, but lagged $Y_{i r}$ values as well:

$$
\ln \left(A V C_{i t}\right)=\gamma_{0}+\gamma^{\mathbf{k}} k_{i t}+\sum_{\tau=1}^{T} \gamma_{\tau}^{d} D_{i t}^{\tau}+\sum_{j=1}^{J} \gamma_{j}^{c} \ln \left(A V C_{i r-j}\right)+\sum_{j=1}^{J} \gamma_{j}^{y} Y_{i r-j}+v_{i t}
$$

Here time dummies control for changes in factor prices that are common to all plants.

Together, equations (10) and (11) describe export market participation patterns and marginal costs realizations for the case of no learning externalities. Estimated as a system, they should reveal whether marginal costs influence the export participation decision, as the model implies, and whether firms typically experience cost reductions once they have begun to service foreign markets, as posited by the learning-by-exporting hypothesis. Tests on the cost coefficients in the participation equation indicate whether firms respond to cost reductions by becoming more likely to export, and tests on the $Y_{i r-j}$ coefficients in the cost function indicate whether exporting experience leads to lower costs. It is, of course, the latter direction of causality that is of primary interest to us.

Serial correlation is likely in both equations because persistent unobserved plant characteristics make some firms consistently low cost and/or consistently prone to exporting, conditioning on observable variables. Hence, we model each disturbance as composed of an unobserved (random) plant effect, $\alpha_{1}$ and $\alpha_{2}$, plus transitory noise: $\eta_{i r}=\alpha_{1 i}+\epsilon_{1 i t}$ and $v_{i t}=\alpha_{2 i}+\epsilon_{2 i t}$. We allow the plant effects and the transitory noise to be correlated across equations. Also, without loss of generality, we impose the normalization $\operatorname{var}\left(\eta_{i r}\right)=1$ so that all coefficients in equation (10) are measured relative to total unexplained variation.

Unfortunately, the combination of lagged dependent variables with serial correlation creates 
special problems in panel data. These lagged variables are themselves functions of the unobserved plant effects, so they are correlated with the disturbance. But this dependence is not captured by equation (10) nor by equation (11) for the first J years of data. We adopt Heckman's (1981a, 1981b) solution to this "initial conditions problem" by adding extra equations to the system that represent $Y_{i}$ through $Y_{i J}$ as functions of $\alpha_{1 i}$ (inter alia), and $A V C_{i I}$ through $A V C_{i}$ as functions of $\alpha_{2 i}$ (inter alia). The result is a variant of Keane, Moffitt and Runkle's (1988) and Sullivan's (1995) estimator. ${ }^{19}$ The system is estimated using maximum likelihood, integrating out the two random effects with Gaussian quadrature. Details of the likelihood function may be found in Appendix III.

\section{B. The Evidence on Learning}

Because we expect the cost function, the profit function, entry costs, and the potential for active learning to differ across industries, we fit our system of equations seperately to each industry in which we have sufficient observations to support inference. We include industries which are relatively intensive in human capital (e.g., Chemicals) as well as those that are not (e.g., Apparel) in order to look for corresponding variation in active learning effects. Although the model can be fit to our Mexican panel, the time period spanned by that data set proved to short to isolate random effects from the history of cost and export market partication. ${ }^{20}$ We therefore focus our attention on the Colombian and Moroccan results reported in Tables 3.1 and 3.2 .

The participation equation yields results similar to those reported elsewhere (Roberts and Tybout, 1984; Roberts, Sullivan and Tybout, 1995). In all countries and in all industries, plants with large capital

\footnotetext{
${ }^{19}$ Sullivan's (1995) estimator does not deal with initial conditions problems in the equation that has a continuous dependent variable; and Keane, Moffit and Runkle's (1988) estimator does not deal with dynamics at all. Otherwise the structure of our estimator is the same.

${ }^{20}$ In Mexico we observe only five years of data, and three of these years are lost to lags on participation and average costs, leaving two in-sample years. Estimates of the model (available upon request) attribute too much explantory power to lagged cost and export participation, and imply that $\operatorname{var}\left(\alpha_{1}\right)=\operatorname{var}\left(\alpha_{2}\right)=0$. Nonetheless, the results concerning the effect of lagged participation on cost realizations are consistent with those obtained in the other countries. The convergence of random effect Probit estimators to simple Probit estimators when T is small is discussed in Guilkey and Murphy (1993).
} 
stocks are more likely to be exporters. One likely interpretation is that there are fixed costs associated with export shipments, and producers who can produces large batches are better able to spread these costs. Consistent with our conceptual framework, plants that have lower marginal costs are more likely to be exporters, other things being equal. But individual lags of this variable are never statistically significant, perhaps because of the high collinearity between them, and, even though in some instances the estimated coefficients alternate in sign, their sum is always negative. ${ }^{21}$ The fact that standard errors for cost coefficients are relatively large for Morocco is consistent with the lack of cost variation across types of firms observed in the graphs discussed earlier in section III.

The effect of export experience is most dramatic for plants that exported last period, and hence face no re-entry costs. In all industries the effect is substantial. In Morocco, the effect is smaller in textiles than in chemicals. This result jibes with our priors that breaking into the foreign textiles market involves less sunk cost than breaking into the chemical markets. Although exporting experience acquired more than one year ago proved marginally significant in earlier work on participation (Roberts and Tybout, 1994), it appears to be unimportant for most industries in the present application. This finding is probably due to the relatively small samples we use here, since the coefficients on lagged participation variables themselves are not systematically smaller in Morocco.

In theory, devaluations should increase the probability of becoming an exporter, but we only find significant effects of the exchange rate in Colombian textiles and apparel industries. These are the goods that Colombia sends north, so it is not surpising that the real exchange rate vis-à-vis the dollar is a strong predictor for both industries. Chemicals, on the other hand, are mainly sold in Latin America and producers in that industry do not show as much responsiveness to real exchange rates. Point estimates of the response to devaluation in Morocco resemble those for Colombia, but have much larger standard errors.

\footnotetext{
${ }^{21}$ One reason these results are less dramatic than our graphs is that here we condition on lagged participation, which is colinear with $A V C$. Put differently, firms with low unit costs tended to be exporters in the past, so recent innovations in $A V C$ have limited explanatory power.
} 
Table 3.1: Estimation Results of Equations (10) and (11), Colombia 1983-91

\begin{tabular}{|c|c|c|c|}
\hline & Chemicals & Textiles & Apparel \\
\hline \multicolumn{4}{|c|}{ Participation Equation } \\
\hline intercept & $-15.06(5.87)^{*}$ & $-4.34(1.33)^{*}$ & $-5.20(1.58)^{*}$ \\
\hline $\ln ($ exchange rate $)$ & $.462(2.27)$ & $3.93(1.14)^{*}$ & $3.60(0.94)^{*}$ \\
\hline $\ln$ (capital stock $\mathrm{it-1}_{1}$ ) & $3.73(0.72)^{*}$ & $1.71(0.34)^{*}$ & $2.03(0.37)^{*}$ \\
\hline $\ln \left(\right.$ age $\left._{\mathrm{it}}\right)$ & $5.94(3.87)$ & $-0.12(0.85)$ & $0.64(1.07)$ \\
\hline $\ln \left(a g e_{i}\right)^{2}$ & $-0.88(0.58)$ & $0.09(0.14)$ & $-0.01(0.18)$ \\
\hline business type $_{i t}$ & $-0.00(0.28)$ & $0.23(0.15)$ & $0.28(0.14)^{*}$ \\
\hline $\ln \left(A V C_{i t-1}\right)$ & $-0.14(0.28)$ & $-0.18(0.18)$ & $-0.05(0.11)$ \\
\hline $\ln \left(A V C_{i t-2}\right)$ & $0.06(0.29)$ & $-0.16(0.18)$ & $-0.10(0.13)$ \\
\hline$\tilde{Y}_{i t-1}$ & $1.86(0.41)^{*}$ & $2.04(0.27)^{*}$ & $1.03(0.25)^{*}$ \\
\hline$\tilde{Y}_{i n-2}$ & $0.18(0.40)$ & $0.25(0.29)$ & $-0.10(0.25)$ \\
\hline$\tilde{Y}_{i t-3}$ & $0.26(0.40)$ & $-0.57(0.46)$ & $-0.20(0.25)$ \\
\hline \multicolumn{4}{|c|}{ Cost Function } \\
\hline intercept & $-0.16(0.13)$ & $-0.33(0.06)^{*}$ & $-0.36(0.06)^{*}$ \\
\hline $\ln$ (capital stock ) & $-0.17(0.11)$ & $0.05(0.04)$ & $0.09(0.06)$ \\
\hline $\ln \left(A V C_{i t-1}\right)$ & $0.36(0.05)^{*}$ & $0.65(0.02)^{*}$ & $0.74(0.02)^{*}$ \\
\hline $\ln \left(A V C_{i t-\nu}\right)$ & $0.45(0.05)^{*}$ & $0.16(0.03)^{*}$ & $0.12(0.03)^{*}$ \\
\hline $\bar{Y}_{i t-1}$ & $0.09(0.05)$ & $0.01(0.03)$ & $0.08(0.03)^{*}$ \\
\hline$\tilde{Y}_{t-2}$ & $0.22(0.09)^{*}$ & $0.04(0.06)$ & $0.01(0.08)$ \\
\hline$\tilde{Y}_{i t-3}$ & $0.11(0.10)$ & $0.06(0.07)$ & $0.01(0.08)$ \\
\hline \multicolumn{4}{|c|}{ Variance-Covariance Matrix for Disturbances } \\
\hline $\operatorname{var}\left(\alpha^{1}\right)$ & 0.298 & 0.167 & 0.574 \\
\hline $\operatorname{var}\left(\alpha^{2}\right)$ & 0.005 & 0.0001 & 0.001 \\
\hline $\operatorname{corr}\left(\alpha^{1}, \alpha^{2}\right)$ & -0.106 & -0.147 & -0.082 \\
\hline $\operatorname{var}\left(\epsilon^{1}\right)$ & 0.702 & 0.823 & 0.426 \\
\hline $\operatorname{var}\left(\epsilon^{2}\right)$ & 0.995 & 0.106 & 0.163 \\
\hline $\operatorname{corr}\left(\epsilon^{1}, \epsilon^{2}\right)$ & 0.180 & -0.110 & -0.026 \\
\hline No. observations & 567 & 1,854 & 2,547 \\
\hline Log-likelihood & -309.61 & -938.45 & $-1,679.24$ \\
\hline
\end{tabular}


Table 3.2: Estimation Results of Equations (10) and (11), Morocco 1984-90

\begin{tabular}{|c|c|c|c|}
\hline & Chemicals & Food & Textiles \\
\hline \multicolumn{4}{|c|}{ Participation Equation } \\
\hline intercept & $17.66(18.18)$ & $16.35(15.04)$ & $16.49(10.05)$ \\
\hline $\ln ($ exchange rate $)$ & $5.69(3.90)$ & $3.58(3.22)$ & $3.50(2.13)$ \\
\hline $\ln \left(\right.$ capital stock $\left._{\mathrm{it}-1}\right)$ & $2.64(0.67)^{*}$ & $1.03(0.46)^{*}$ & $2.45(0.43)^{*}$ \\
\hline $\ln \left(\right.$ age $\left._{\mathrm{it}}\right)$ & $2.45(3.23)$ & $-1.56(1.73)$ & $-2.09(1.47)$ \\
\hline $\ln \left(\text { age } e_{i}\right)^{2}$ & $-0.39(0.48)$ & $0.28(0.26)$ & $0.35(0.24)$ \\
\hline business type $_{\text {it }}$ & $0.81(0.70)$ & $0.26(0.15)$ & $0.07(0.16)$ \\
\hline $\ln \left(A V C_{i n-D}\right)$ & $-1.16(0.60)$ & $-0.18(0.42)$ & $0.06(0.18)$ \\
\hline $\ln \left(A V C_{i t-2}\right)$ & $-1.05(0.89)$ & $0.92(0.47)$ & $-0.24(0.30)$ \\
\hline$\tilde{Y}_{i t-1}$ & $1.14(0.45)^{*}$ & $1.25(0.54)^{*}$ & $0.91(0.36)^{*}$ \\
\hline$\tilde{Y}_{i t-2}$ & $0.27(0.36)$ & $1.25(0.51)^{*}$ & $0.50(0.28)$ \\
\hline$\tilde{Y}_{i t-3}$ & $0.28(0.35)$ & $0.67(0.47)$ & $0.02(0.28)$ \\
\hline \multicolumn{4}{|c|}{ Cost Function } \\
\hline intercept & $0.05(0.03)$ & $-0.07(0.03)^{*}$ & $-0.12(0.03)^{*}$ \\
\hline $\ln \left(\right.$ capital stock $\left.\mathrm{i}_{\mathrm{it}}\right)$ & $-0.06(0.04)$ & $-0.16\left((0.04)^{*}\right.$ & $-0.07(0.04)$ \\
\hline $\ln \left(A V C_{i-1}\right)$ & $0.39(0.05)^{*}$ & $0.20(0.05)^{*}$ & $0.15(0.04)^{*}$ \\
\hline $\ln \left(A V C_{i t-2}\right)$ & $0.40(0.07)^{*}$ & $0.25(0.05)^{*}$ & $0.07(0.05)$ \\
\hline$\tilde{Y}_{i-1}$ & $-0.02(0.03)$ & $0.12(0.02)^{*}$ & $-0.02(0.02)$ \\
\hline $\bar{Y}_{i t-2}$ & $0.03(0.05)$ & $0.02(0.04)$ & $0.00(0.05)$ \\
\hline$\tilde{Y}_{i t-3}$ & $0.02(0.04)$ & $0.01(0.10)$ & $-0.12(0.06)$ \\
\hline \multicolumn{4}{|c|}{ Variance-Covariance Matrix for Disturbances } \\
\hline $\operatorname{var}\left(\alpha^{1}\right)$ & 0.546 & 0.724 & 0.677 \\
\hline $\operatorname{var}\left(\alpha^{2}\right)$ & 0.0001 & 0.003 & 0.001 \\
\hline $\operatorname{corr}\left(\alpha^{1}, \alpha^{2}\right)$ & 0.046 & -0.559 & -0.590 \\
\hline $\operatorname{var}\left(\epsilon^{1}\right)$ & 0.454 & 0.276 & 0.323 \\
\hline $\operatorname{var}\left(\epsilon^{2}\right)$ & 0.024 & 0.022 & 0.057 \\
\hline $\operatorname{corr}\left(\epsilon^{1}, \epsilon^{2}\right)$ & -0.019 & -0.040 & -0.057 \\
\hline No. observations & 637 & 1,169 & 1,722 \\
\hline Log-likelihood & 69.13 & 117.79 & -517.87 \\
\hline
\end{tabular}


Now consider the cost equation, which is the focus of our analysis. ${ }^{22}$ As expected, plants with larger capital stocks tend to have lower marginal costs, although there are some insignificant coefficients. Also, conditioning on capital stocks and unobserved plant effects, marginal costs appear to follow a second-order, or higher, autorregressive process. ${ }^{23}$ But, critically, exporting history contributes little to the explanation of marginal costs once we have conditioned on these variables. Indeed, in the few instances where lagged experience is statistically significant, the coefficient suggests that exporting increases costs.

Might this cost increase be a statistical artifact? One possibility is that we systematically overestimate the price of exported products, so that when producers start exporting the real value of their output is systematically under-estimated, causing average costs to be overstated and labor productivity to be understated. ${ }^{24}$ Another source of bias derives from the fact that we are not measuring total costs. If the production technology for exports is more labor-intensive (or skilled-labor intensive) than the technology for domestic goods produced by the same firm, we might miss offsetting reductions in capital costs by focusing exclusively on labor and materials. Third, workers may capture efficiency gains as higher wages, leaving average variable costs unaffected. Finally, we may well be picking up some of the sunk entry costs associated with becoming an exporter in our variable cost measure. But in Colombia the

\footnotetext{
${ }^{22}$ One estimation detail worth noting is that the variance of the random effect in our cost equation is always very close to zero. This is apparently because the lagged cost variables pick up all of the relevant heterogeneity. One implication is that we really didn't need to estimate the cost functions jointly with the participation equation: there is no reason to think that lagged participation is correlated with the disturbance.

${ }^{23}$ Indeed, in preliminary work, a third lag of the cost variable was sometimes statistically significant. Because the results and conclusions are not significantly changed by the inclusion of a third lag of costs, and because of the increased complexity of the estimation, we decided to work with the more parsimonous specification. The same apllies to the use of year dummies instead of the exchange rate.

${ }^{24}$ Given our methodology for construction of price indices, this could happen if we over-estimated the change in the real exchange rate between the base year and the current year. Note, that it is unlikely to result from changes in product quality. If quality improvements accompany foreign market entry, they should increase both the numerator and the denominator of $A V C$, so this phenomenon need not be a tendency to mis-interpret quality improvements as adverse cost shocks.
} 
coefficients on all three lags of export market participation are positive, so for at least three years, these entry costs are not offset by productivity gains due to learning-by-exporting effects.

In sum, it is hard to reconcile our results with the presence of strong learning-by-exporting effects. If they are not driven by measurement problems, these estimates suggest that negative cost shocks can Granger cause increases in the expected return from exporting. But the act of exporting does not Granger cause reductions in marginal costs.

\section{The Evidence on Externalities}

In order to test for regional and industry spillover effects, we re-specified equations (10) and (11) to include regional and industry export intensity variables. Export intensity was measured as the percentage of firms in the industry/region that were exporting in the particular year. These variables were added to the participation equation to test whether sunk entry costs depend upon exporting activity by other firms. They were also added to the cost function to test whether all firms enjoy cost reductions when some firms export. To control for permanent, unobserved regional effects like access to ports, regional dummies were also included.

Adding our measure of industry-specific export activity to the model increased the colinearity of the explanatory variable set because, like the exchange rate, it is common to all firms in the industry. The (absolute) correlation between these two variables lies between 0.66 and 0.76 in Colombia, and between 0.62 and 0.91 in Morocco, depending upon the industry. These correlations, while high, do not prohibit estimation. However, the condition number of the moment matrix of the regressors--the square root of the ratio of the largest to the smallest characteristic root--lies between 648 ad 1018 in Morocco, but only between 47 and 56 in Colombia. ${ }^{25}$ In addition, the estimated coefficients of the exchange rate and the

\footnotetext{
${ }^{25}$ For the purposes of these calculations the regressors include only a constant, the exchange rate, the proportion of exporters in the industry, the proportion of exporters in the region, and the regional dummies. A condition number above 30 suggests potential multicolinearity problems (Belsley, Kuh and Welsch , 1980).
} 
spillover variables in Morocco were absurdly high and imprecisely estimated. For these reasons, we decided to focus the spillover analysis on Colombia only. ${ }^{26}$

Suppressing the non-exernality coefficients, which are similar to those in Table 3.1, we report coefficients for the Colombian externality variables in Table 4. All but one of the externality coefficients in the participation question are positive; however, only one is significant. Nonetheless, this seems to provide some evidence that the presence of many exporters increases a firm's chances of being an exporter itself. These results buttress Aitken, Hanson and Harrison's (forthcoming) conclusions based on cross-sectional analysis of Mexican data.

The same cannot be said of the effect on average variable costs. Four out of six coefficients are positive, suggesting that high export intensity actually raises costs. The chemical industry is particularly noteworthy because the two coefficients are both significant and they have counteracting effects. Unit production costs are reduced by export intensity in the region, perhaps because of demonstration effects, and the development of better transport services for exporters. On the other hand, the presence of other chemicals exporters appears to increase unit costs. One interpretation is that other exporters in one's own industry bid up the local cost of specialized inputs. These possibilities are intriguing, but given the inconsistences across industries we refrain from generalization.

${ }^{26}$ Using the proportion of exporters in the region instead of the proportion of exporters in the industry is not feasible in Morocco because most firms are located in one region. For example, 90 percent of the chemical firms and 70 percent of the textile firms are in the Casablanca area. 
Table 4: Coefficients of Spillover Variables, Colombia

\begin{tabular}{|c|c|c|c|}
\hline & Chemicals & Textiles & Apparel \\
\hline \multicolumn{4}{|c|}{ Participation Equation } \\
\hline $\begin{array}{l}\text { \% Exporters, } \\
\text { Industry }\end{array}$ & $-2.03(3.07)$ & $0.04(6.07)$ & $1.63(1.30)$ \\
\hline $\begin{array}{l}\text { \% Exporters, } \\
\text { Region }\end{array}$ & $2.74(5.00)$ & $6.14(10.37)$ & $5.01(0.82)^{*}$ \\
\hline \multicolumn{4}{|c|}{ Cost Function } \\
\hline $\begin{array}{l}\text { \% Exporters, } \\
\text { Industry }\end{array}$ & $2.72(0.65)^{*}$ & $0.24(0.85)$ & $-0.43(0.62)$ \\
\hline $\begin{array}{l}\text { \% Exporters, } \\
\text { Region }\end{array}$ & $-3.31(0.94)^{*}$ & $1.02(1.30)$ & $1.76(1.30)$ \\
\hline \multicolumn{4}{|c|}{ Log-likelihood } \\
\hline & -289.28 & -924.65 & $-1,603.87$ \\
\hline
\end{tabular}

Standard errors are in parentheses.

* significant at the .05 level.

\section{Summary and Conclusions}

Micro data in developing countries often show that exporting firms are more efficient than nonexporting firms. This study confirms that pattern, and adds the finding that plants which cease exporting are typically less efficient, sometimes dramatically so. But more importantly, this study addresses the question of whether the association between exporting and efficiency reflects causation flowing from exporting experience to improvements in performance. Surprisingly, despite many anecdotes in the literature to the contrary, we find scant evidence of such a causality pattern.

If learning-by-exporting is important, then the stochastic processes that generate cost and productivity trajectories should improve with changes in exporting status. To get some sense for the nature of the respone, we began by plotting cost and exporting trajectories from actual plant-level panel data from Colombia, Morocco and Mexico. We found that plants which begin exporting tend to have relatively low average variable cost, and plants that cease exporting are becoming increasingly high cost, 
as implied by the model. Similar patterns emerged when we used labor productivity as our performance

measure. However, cost and productivity trajectories generally did not continue to change after entering foreign markets. That is, the patterns we found in the actual data resembled our no-learning-by-exporting scenario, under which the positive association between export status and productivity is due solely to the self-selection of relatively more efficient plants into foreign markets.

To formally test whether the association between exporting and efficiency reflects more than self-selection, we simultaneously estimated an autoregressive cost function and a dynamic discrete choice equation that characterized export market participation decisions. Exporting history did not significantly shift the cost function, and to the extent that it did, the shift was in the "wrong" direction. The association between exporting and efficiency is thus most plausibly explained as low-cost producers choosing to become exporters.

Finally, looking for evidence of externalities, we found that the presence of other exporters might make it easier for domestically-oriented firms to break into foreign markets. In principle, this opens the possibility that export promotion policies are welfare improving. On the other hand, the presence of exporters does not appear to reduce the unit production costs of neighboring firms in most instances. So if exporters act as conduits of foreign knowledge to local producers, this effect is weak, slow, or masked by other cost-increasing spillovers of export activity. 


\section{References}

Aitken, Brian, Gordon H. Hanson, and Ann Harrison (forthcoming). "Spillovers, Foreign Investment, and Export Behavior." Journal of International Economics.

Aw, Bee-Yan and Hwang, A.R. (1995), "Productivity and the Export Market: A Firm-Level Analysis"Journal of Development Economics 47: 313-332.

Baldwin, Richard (1989) “Sunk Cost Hysteresis,” NBER Working Paper No. 2911.

Belsley, D.A., E. Kuh and R.E. Welsch (1980). Regression Diagnostics: Identifying Data and Sources of Colinearity. New York: Wiley.

Bernard, Andrew B. and J. Bradford Jensen (1995), "Exceptional Exporter Performance: Cause, Effects, or Both?", mimeo.

Chen, T. and D. Tang (1987), "Comparing Technical Efficiency between Import-Substitution and Export Oriented Firms in a Developing Country" Journal of Development Economics 26: 277-89.

Dixit, A. (1989), "Exit and Entry Decisions Under Uncertainty" Journal of Political Economy 97: 620-38.

Evanson, Robert. and Larry Westphal (1995) "Technological Change and Technology Strategy," in T.N. Srinivasan and Jere Bherman, eds., Handbook of Development Economics. Volume 3.

Amsterdam: North-Holland.

Guilkey, D. And J.L. Murphy (1993). "Estimation and Testing in the Random Effects Probit Model," Journal of Econometrics 59: 301-17.

Haddad, M. (1993) "How Trade Liberalization Affected Productivity in Morocco." Policy Research Working Paper 1096, The World Bank.

Handoussa, H., M. Nishimizu and J. Page (1986), "Productivity Change in Egyptian Public Sector Industries after the 'Opening'" Journal of Development Economics 20: 53-74.

Heckman, J. (1981a), "Statistical Models for Discrete Panel Data" in C. Manski and D. McFadden, eds., Structural Analysis of Discrete Data with Econometric Applications. Cambridge MA: MIT Press.

(1981b), "The Incidental Parameters problem and the Problem of Initial Conditions in Estimating a Discrete Time-Discrete Data Stochastic Process" in C. Manski and D. McFadden, eds., Structural Analysis of Discrete Data with Econometric Applications. Cambridge MA: MIT Press.

Keane, Micheal, Robert Moffit and David Runkle (1988) "Real Wages over the Business Cycle: Estimating the Impact of Heterogeneity with Micro Data," Journal of Political Economy 96: 1232-66. 
Krugman, Paul (1989) Exchange rate Instability. Cambridge: MIT Press.

Rhee, Ross-Larson and Pursell (1984) Korea's Competitive Edge: Managing the Entry into World Markets. Baltimore: Johns Hopkins University Press.

Roberts, Mark, Theresa Sullivan and James Tybout (1995) "What Makes Exports Boom? Evidence from Plant-level Panel Data, The World Bank, processed.

Roberts, Mark and James Tybout (1995) "An Empirical Model of Sunk Costs and the Decision to Export," PRD Working Paper 1436, The World Bank.

Roberts, Mark and James Tybout, eds. (forthcoming) Industrial Evolution in Developing Countries. New York: Oxford U. Press.

Rust, J. (1994), "Structural estimation of Markov Decision Processes", in R. Engle and D. McFadden, eds., Handbook of Econometrics, Volume IV Vol IV, Elsevier.

Sullivan, Theresa (1995) "Micro-foundations of Export Supply in Morocco," Ph.D. dissertation, Georgetown University.

Tybout, J. and M.D. Westbrook (1995) "Trade Liberalization and Dimensions of Efficiency Change in Mexican Manufacturing Industries." Journal of International Economics 31 (August) 53-78.

World Bank (1993) The East Asian Miracle. New York: Oxford University Press.

World Bank (1994) Kingdom of Morocco -- Republic of Tunisia, Export Growth: Determinants and Prospects. Report No. 12947-MNA. 


\section{Appendix I: The Dynamic Optimization Problem}

\section{A. The Numerical Solution}

In the type of problem presented in section II, the optimal participation policy usually involves two trigger levels defined, for our purposes, in terms of marginal cost levels, $C_{\mathrm{L}}<C_{U}$, such that a nonexporting plant will start exporting when its costs are no larger than $C_{\mathrm{L}}$, and an exporting plant will cease exporting when its costs equal or are larger than $C_{U}$.

We will assume that this is indeed the type of policy followed by the plant and focus on computing the trigger points. For this pupose, we assume that $c$ is a random variable that takes any one of $\mathrm{K}$ discrete values $c_{1}, \ldots, c_{\mathrm{K}}$, and evolves over time according to a stationary Markov process with transition probability matrix $\mathbf{P}=\left[\mathrm{p}_{\mathrm{j}}\right]$, where $\mathrm{p}_{\mathrm{ij}}$ denotes the probability of observing $c_{\mathrm{i}}$ at $\mathrm{t}$ given that $c_{\mathrm{j}}$ occurred at $\mathrm{t}-1$.

The value of any particular policy $\left(C_{L} C_{U}\right)$ is

$$
V_{L U}\left(c_{r}, Y_{t-1}\right)=E \sum_{\tau=0}^{\infty} \delta^{\tau} Y_{t+\tau}\left(\pi^{f}\left(c_{t+\tau}, z\right)-M-\left(1-Y_{t+\tau-1}\right) F\right)
$$

where expectations are taken over marginal costs conditional on the value of the current marginal cost and the export status at the beginning of period $t$, and where,

$$
Y_{t}=\left\{\begin{array}{l}
1 \text { if } c_{t} \leq c_{L} \text { or }\left\{\text { if } c_{t}<c_{U} \text { and } Y_{t-1}=1\right\} \\
0 \text { if } c_{t} \geq c_{U} \text { or }\left\{\text { if } c_{t}>c_{L} \text { and } Y_{t-1}=0\right\}
\end{array}\right.
$$

is the binary variable that takes the value of one if the plant is exporting and 0 otherwise. We treat the demand shifter $z^{f}$ as fixed and we ignore learning effects on domestic market profits. 
We now show how to compute $\mathrm{V}_{\mathrm{LU}}\left(c_{\mathrm{t}}, \mathrm{Y}_{\mathrm{t}-1}\right)$ for an arbitrary policy $\left(C_{L} C_{U}\right)$ and given parameters. ${ }^{27}$ Define $s_{t}=\left(c_{t}, Y_{t-1}\right)$ as the state variable in period $t$. Let current returns under an arbitrary policy be $R_{L U}\left(s_{t}\right)$ which equals $Y_{t}\left(\pi\left(c_{t}\right)-M\right)$ if $Y_{t-1}=1$ or $Y_{t}\left(\pi\left(c_{t}\right)-M-F\right)$ if $Y_{t-1}=0$ (recall that, from (A2), $Y_{t}$ is a function of $s_{1}$ ). Then, the policy's value equals the discounted expected value of the sequence of returns $R_{L U}\left(s_{t+\tau}\right)$. Because $c$ and $Y$ are discrete, $s_{t+\tau}$ takes any one of $2 \mathrm{~K}$ possible values. Let $s=$ $\left(\mathrm{s}_{1}=\left(c_{1}, 0\right), \ldots, \mathrm{s}_{\mathrm{K}}=\left(c_{K}, 0\right), \mathrm{s}_{\mathrm{K}+1}=\left(c_{l}, 1\right), \ldots, \mathrm{s}_{2 \mathrm{~K}}=\left(c_{K}, 1\right)\right)^{\prime}$, be the $2 \mathrm{Kx}$ l vector of state values with coordinates s, $\mathrm{i}=1, \ldots, 2 \mathrm{~K}$. Then, for example, the discounted expected value of tomorrow's returns is simply an average of the $2 \mathrm{~K}$ possible returns weighted by the one step-ahead (conditional) probabilities of being next period in state $\mathrm{s}_{\mathrm{i}}$, given that today's state is $\mathrm{S}$ and that the plant uses the policy $\left(C_{L}, C_{U}\right)$. Denoting these probabilities by $e_{i j}$ this values is, ${ }^{28}$

$$
\delta \sum_{i=1}^{2 K} e_{i j} R_{L U}\left(s_{i}\right)
$$

Notice that time per-se, has no effect on the value of a policy; only the value taken by the state variable matters, i.e., the problem is stationary. Also, the vector s follows a Markov process. Hence, from the $2 \mathrm{~K} \times 2 \mathrm{~K}$ one-step transition matrix for the state vector $\mathrm{s}$, denoted by $\mathrm{E}_{\mathrm{LU}}$, one can easily obtain the n-step transition probability matrix $\mathrm{E}_{\mathrm{LU}}$ and compute the expected discounted value of a policy for any initial state as,

$$
V_{L U}(s)=R_{L U}(s)+\delta E_{L U} R_{L U}(s)+\delta^{2} E_{L U}^{2} R_{L U}(s)+\ldots=\left[I-\delta E_{L U}\right]^{-1} R_{L U}(s)
$$

where $R_{L U}(s)$ is the $2 K \times 1$ vector of returns at each possible value of the state variable and $V_{L U}(s)$ is a

\footnotetext{
${ }^{27}$ Based on Rust (1994).
}

${ }^{28}$ Although it is omitted for notational convenience, it should be understood that $e_{i j}$ depends on the values of the trigger points and should therefore be also indexed by $(L, U)$. For example, if $\mathrm{L}=3$ then, when $\mathrm{c}=\mathrm{c}_{1}$, the plant will be exporting. Hence, the probability of being in state $s_{1}$ is zero since $\left(c_{1}, 0\right)$ can never happen. 
$2 \mathrm{Kx} 1$ vector giving the value of the policy at each initial state. For example, the first (last) coordinate of $\mathrm{V}_{\mathrm{LU}}(\mathrm{s})$ is the value of the policy given the initial state $\left(c_{l}, 0\right)\left(\left(c_{K}, 1\right)\right)$. Hence, if $\mathrm{E}_{\mathrm{LU}}$ and $\mathrm{R}(\mathrm{s})$ are known $\mathrm{V}_{\mathrm{LU}}(\mathrm{s})$ can be easily computed.

The $\mathrm{E}_{\mathrm{Lu}}$ probability matrix is derived a follows. Let $\mathrm{P}_{\mathrm{j}}=\operatorname{Pr}\left(\mathrm{c}_{\mathrm{t}}=\mathrm{c}_{\mathrm{i}} / \mathrm{c}_{\mathrm{t}-1}=\mathrm{c}_{\mathrm{j}}\right)$ and let $e_{l \mathrm{k}}=\operatorname{Pr}\left(\mathrm{s}_{\mathrm{t}}=\mathrm{s}_{\mathrm{l}} / \mathrm{s}_{\mathrm{t}-}\right.$ $\left.{ }_{1}=s_{k}\right)$. Let $p_{j}=\left(p_{j 1}, \ldots, p_{j K}\right)$, be the $j^{j t}$ row of the matrix $P$. Then, for any numbers $0 \leq L \leq U \leq K, E_{L U}$ equals,

$$
E_{L U}=\left[\begin{array}{cc}
0_{L x K} & 0_{(U-1) \times K} \\
p_{L+1 .} & p_{U .} \\
\cdot & \cdot \\
\cdot & \cdot \\
p_{K} & p_{K .} \\
p_{1} & p_{1} \\
\cdot & \cdot \\
\cdot & \cdot \\
p_{L .} & p_{(U-1) .} \\
0_{(K-L) \times K} & 0_{(K-U-1) \times K}
\end{array}\right]
$$

$$
\mathrm{V}_{\mathrm{LU}}(\mathrm{c}, \mathrm{Y}) \text { is calculated for all policies satisfying } 1 \leq \mathrm{L}<\mathrm{U} \leq \mathrm{K} \text {, a total of } \mathrm{K}(\mathrm{K}+1) / 2-\mathrm{K}
$$

alternatives. For each state $\mathrm{s}_{1}=\left(c_{i}, \mathrm{Y}\right)$ we determine the (relevant) trigger cost delivering the maximum value among all possible policies, i.e., $q_{\mathrm{L}}$ for states with $\mathrm{Y}=0$ and $\mathrm{c}_{\mathrm{U}}$ for states with $\mathrm{Y}=1$. These trigger points define the optimal participation policy of the plant and it amounts to the sequence of entry/exit decisions $\left\{\mathrm{Y}_{\mathrm{t}+\tau}\right\}$ that maximizes the expected discounted value of the plant. That is,

$$
\begin{aligned}
& L\left(s_{i}\right)=\operatorname{argmax}_{L} V_{L U}\left(s_{i}\right) \quad i=1, \ldots, K . \\
& U\left(s_{i}\right)=\operatorname{argmax}_{U} V_{L U}\left(s_{i}\right) \quad i=K+1, \ldots, 2 K .
\end{aligned}
$$


Notice that the trigger points in (A6) are expressed in terms of the indices of the cost vector. From (A6) we can infer which states have probability zero under the optimal policy. States with $\mathrm{Y}=0$ and costs low enough so that $c_{i} \leq C_{L(c i, 0)}$ and, conversely, states with $\mathrm{Y}=1$ and $c_{i} \geq C_{U(c, 1)}$ have probability zero of occurring.

At this point a numerical example can be illustrative. Consider the case where $K=10$ and the ten possible realizations of the marginal costs are $(1,2, \ldots, 10)$. Assume also that given a cost $q$ today the plant can move only to neighboring $\operatorname{costs} c_{i-1}$ or $c_{i+1}$ with probability $p$ or remain with the same cost with probability $1-2 p$. The optimal trigger points associated with each realization of $\$=\left(c_{i}, \mathrm{Y}\right)$ are shown in Table A1, for $p=0.3$.

Table A1: Trigger Points

\begin{tabular}{|c|c|c||}
\hline $\begin{array}{c}\text { State } \\
\mathrm{s}_{\mathrm{t}}=\left(c_{\mathrm{v}} \mathrm{Y}_{\mathrm{t}-1}\right)\end{array}$ & $\begin{array}{c}\text { Trigger } \\
\text { Point }^{29} \\
\mathrm{C}_{\mathrm{L}(\mathrm{s})} \text { or }^{\mathrm{C}_{\mathrm{U}(\mathrm{s})}}\end{array}$ & $\begin{array}{c}\text { Decision } \\
\mathrm{Y}_{\mathrm{t}}\end{array}$ \\
\hline$(1,0)$ & 3 & 1 \\
$(2,0)$ & 3 & 1 \\
$(3,0)$ & 2 & 0 \\
$(4,0)$ to $(10,0)$ & 3 & 0 \\
$(1,1)$ to $(3,1)$ & 4 & 1 \\
$(4,1)$ to $(10,1)$ & 4 & 0 \\
\hline
\end{tabular}

${ }^{29}$ Notice that with the current parametrization of marginal costs the trigger cost and the trigger point are the same, i.e. $c_{L}=L$ and $c_{U}=U$. 
Non-exporters facing costs equal or lower than 2 will enter the export market immediately since their marginal costs are lower or equal than their trigger points. Plants with $c \geq 3$, will remain outside the export market. Exporting plants will remain in the market till their cost raise to 4 or more, at which level they will cease exporting. Thus, a non-exporting plant with $c \leq 2$ will enter the export market and an exporting plant with $c \geq 4$ will quit exporting $\left(C_{L}=2\right.$ and $\left.C_{U}=4\right)$. Table Al fully characterizes the dynamic process followed by the plant.

\section{B. The Structure of our Simulations}

Our simulations are based on the numerical example presented above. The critical issue is how to represent the stochastic cost process summarized by equation (3). Our strategy is to treat costs as following a first-order Markov process that, in the case of learning, is relatively favorable to exporting firms. Specifically, we discretize $c_{l}$ into $K$ possible realizations $\left(c_{l}, \ldots, c_{K}\right)$ and define a transition matrix $\mathbf{P}_{\mathbf{0}}$ that governs movements between the alternative values from one period to the next. This matrix is assumed to be band-diagonal: given a $\operatorname{cost} q_{\mathrm{i}}$ today the plant can move only to neighboring costs $c_{i-1}$ or $c_{i+1}$ with probability $p$ or remain with the same cost with probability $1-2 p$. Note that this specification does not allow us to explore the effects of higher order cost processes. Recall, however, that, our econometric tests in section IV do not suffer from this limitation.

When there is no learning-by-exporting, the $\mathbf{P}_{\mathbf{0}}$ matrix described above applies to all firms. But in the learning case, we let the probability of obtaining a lower cost next period be relatively large for exporters. ${ }^{30}$ We analyze three alternative ways in which the matrix $\mathbf{P}_{0}$ changes into the matrix $\mathbf{P}_{1}$, where $\mathbf{P}_{1}$ is stochastically better than $\mathbf{P}_{\mathbf{0}}$. In the first case (learning model $I$ ), the probability of moving to a lower cost level for exporters is $p+\Delta$, and the probability of moving to a higher cost level to $p-\Delta$. The

${ }^{30}$ Duration in the export market or volume of cumulative exports do not have additional effects. 
second case (learning model $I$ ) spreads these transition probabilities to $p+2 \Delta$ and $p-2 \Delta$, respectively. Finally, the third case (learning model III) makes $c_{1}$ an absorbing state so that plants which achieve the lowest cost remain at that cost forever; the other columns of $\mathbf{P}_{1}$ are as in the no-learning case. This is the purest instance of technological catch-up through exporting: once the best-practice technology is achieved, the catching up is accomplished. The values we assume for $p, \Delta$. and other model parameters are given in Table A2.31

Table A2 : Parameters Values for Simulations

\begin{tabular}{|c|c|c|c|c|c|c|c|c|}
\hline$z^{f}$ & $\sigma^{f}$ & $\mathrm{M}$ & $\mathrm{F}$ & $\delta$ & $\mathrm{p}$ & $\Delta$ & $\mathrm{K}$ & $c_{l}, \ldots, c_{k}$ \\
\hline 30 & 2 & 2 & 2.1 & 0.95 & 0.3 & 0.1 & 10 & $1, \ldots, 10$ \\
\hline
\end{tabular}

With the optimal behavioral rules (A6) and the parameter values in hand, we simulate the dynamic process followed by a plant. We start form an initial state in period $1, \mathrm{~s}_{1}=\left(\mathrm{c}_{1}, \mathrm{Y}_{0}\right)$ randomly selected among the $2 \mathrm{~K}$ possibilities. ${ }^{32}$ The optimal trigger value for this state is obtained from (A6) and compared to $c_{1}$. The result from this comparison tells us whether or not the plant changes its export status from that given by $Y_{0}$. This is how $Y_{1}=Y\left(s_{1}\right)$ is determined. Assuming that all these decisions are made at the beginning of period $t, Y_{1}$ is then the export status of the plant during period $1{ }^{33} c_{2}$ is now randomly drawn according to the probabilities in the column of the transition matrix $\mathbf{P}$ that corresponds to $\mathrm{c}_{1}$, and $\mathbf{s}_{2}$ $=\left(c_{2}, Y_{1}\right)$ is thus obtained. Following the same steps as in period $1, Y_{3}=Y\left(s_{2}\right)$ is generated and so on. In this fashion, we obtain for each plant a time series of $\left\{c_{1}, Y_{1}\right\}$. For each hypothetical plant, we simulate

${ }^{31}$ Becasue $\mathrm{c}^{1-0}$ and $\mathrm{z}$ enter the profit function (1) symmetrically we treat $\mathrm{z}$ as fixed in the simulations since its randomization does not change the qualitative aspects of the excercise.

32 Notice that subscripts now indicate time periods.

${ }^{33}$ Alternatively, we can introduce a one-period lag and make $Y_{1}$ the export status during period 2. 
61 periods. In order to take account of any possible effect from the initial state, we discard the first 50 periods and are left with 11 observations on $c$ and $\mathrm{Y}$. For each of the four learning regimes, we repeat this process 2,000 times. The number of observations corresponds approximately to the number of plants in our actual (non-simulated) data and to the typical length of the time-series data available for each plant.

In order to look at the patterns of association between exporting status and costs under our alternative assumptions about learning-by-exporting, and to facilitate comparison between simulated and actual data, we sort trajectories according to the five varieties of plants described in table 2 in the text. Next, for each plant we re-define time zero to be the year in which a change in export status takes place, and isolate seven-year blocks of time, running from three years prior to the status change $(t=-3)$ to three years after $(t=3) \cdot{ }^{34}$ For non-exporters and for exporters there is no change in status, so we take the seven years in the middle of the eleven-years period. Finally, after re-indexing time in this manner, we average the simulated marginal cost data by plant type and plot them against time. ${ }^{35}$

\section{The Simulations}

Figure A1 summarizes our simulations for the case of no learning. ${ }^{36}$ Note that non-exporters and exiting firms have higher production costs than exporters, but exiting firms maintain a cost advantage over perpetual non-exporters. Without learning effects, producers exit when drawing a $c \geq 4$. More important for our purposes is the constancy of the marginal cost trajectory for entrants after period 0 , exporting.

${ }^{34}$ Thus for entrants, period 0 indicates the first year exporting and for exitors it indicates the first year not

${ }^{35}$ Since the entry/exit decisions occur in different periods we are averaging costs from different years but equally distant from the period in which the plant changed export status. Entrants were required to have at least 4 years exporting and 3 years non-exporting while exitors were required to have at least 4 years non-exporting and 3 years exporting.

36 Switching firms generally look like exporters, so we omit them to reduce clutter. 
Appendix I: The Dynamic Optimization Problem

their entry time. In order to become an exporter, a plant has to draw a cost equal to or below 2 and selecting plants that eventually enter the export market induces the negative slope in the cost trajectory prior to period 0 . After entry, there does not seem to be a significant change in production costs. In short, the simulations in figure $\mathrm{A} 1$ reflect the premise of our no-learning transition matrix: becoming an exporter does not have any significant effects on the stochastic cost process. ${ }^{37}$

Notice that, given our transition matrices, it typically takes more than one period of declining costs to reach the entry threshold. Hence the negative slope of the cost trajectory for entrants prior to entry is a consequence of our grouping criteria and not of leaming-effects or sunk-entry costs. ${ }^{3 \mathrm{~B}}$

Figures A2.1-A2.3 show that the main difference between the passive and active model of export participation is that entrants continue to lower their costs after entering the export market. The pattern of cost trajectories for the other types of plants does not change much with the introduction of learning effects. In particular, it remains true that exporters have systematically lower cost than non-exporters, and exitors experience cost deterioration prior to their exit. Interestingly, even with learning effects, the rate of reduction in marginal costs slows when firms become exporters. This illusory negative effect of becoming an exporter is simply a consequence of the selectivity effects. To reach marginal cost levels low enough to become an exporter, firms must typically experience several consecutive years of cost reductions. Table A3 summarizes the results of the simulations.

37 We caution that if costs followed a second-order process they might continue to fall after entry because of the lingering effects of pre-entry cost reductions.

38 The same reasoning explains the rising cost prior to exit time for exiting plants, while the flatness of the cost trajectory after entry reflects the symmetric first-order markov process followed by costs. 
Figure A1: Simulated Path of Costs No-Learning Model

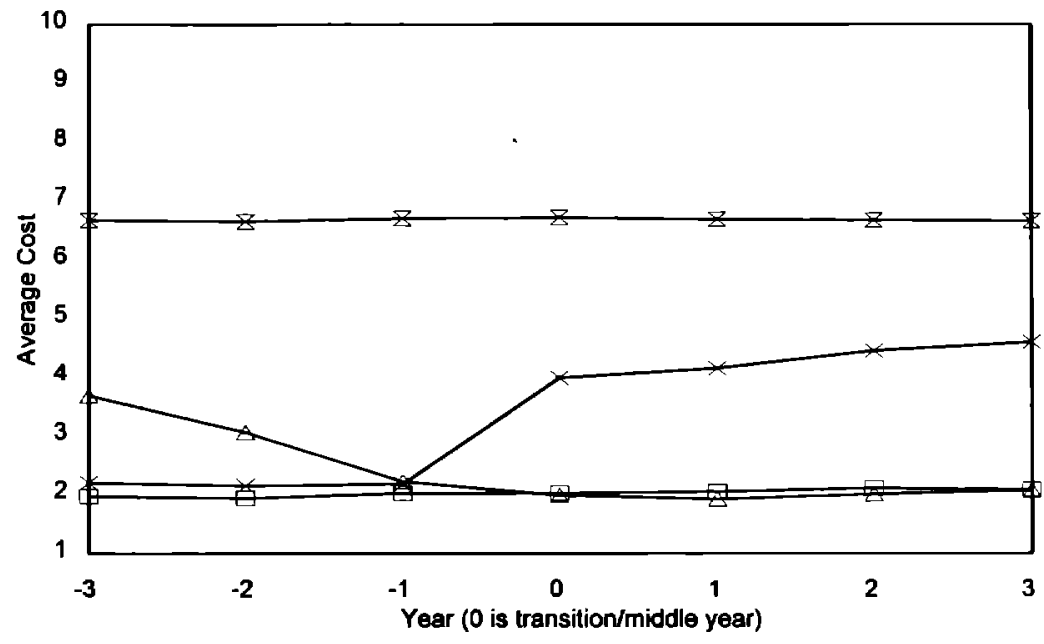

Z- Non-exporters- $\square$ - Exporters $\quad \Delta$ Entrants $\quad \longrightarrow$ Quitters

Figure A2.1: Simulated Path of Costs Leaming Model I

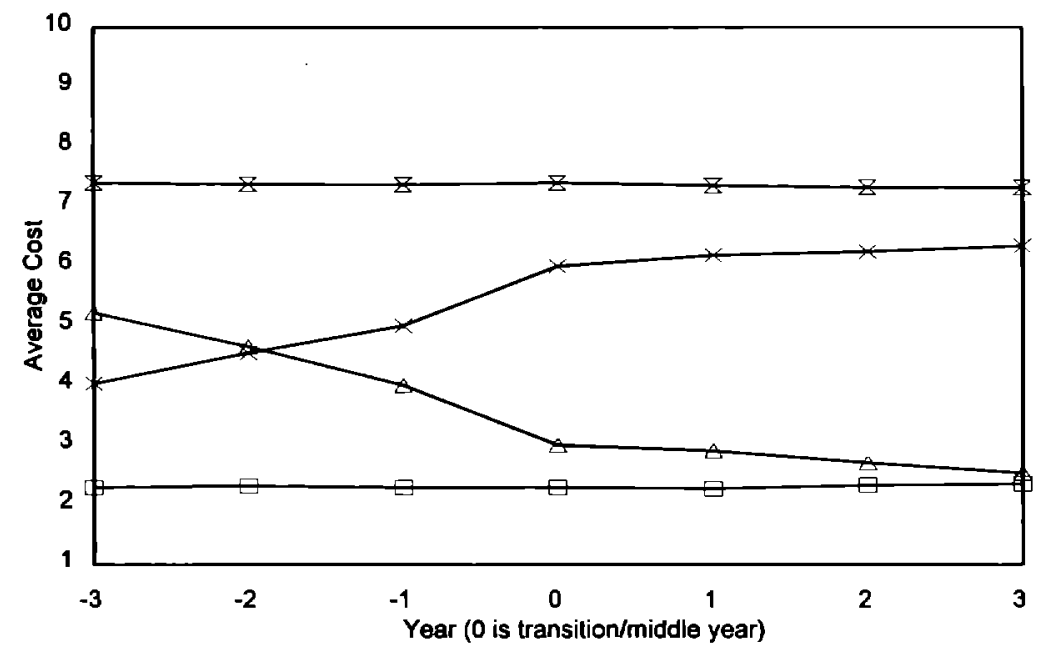

Non-exporterse Exporters $\triangle$ Entrants $\rightarrow$ Quilters 
Figure A2.2: Simulated Path of Costs LeamIng Model II

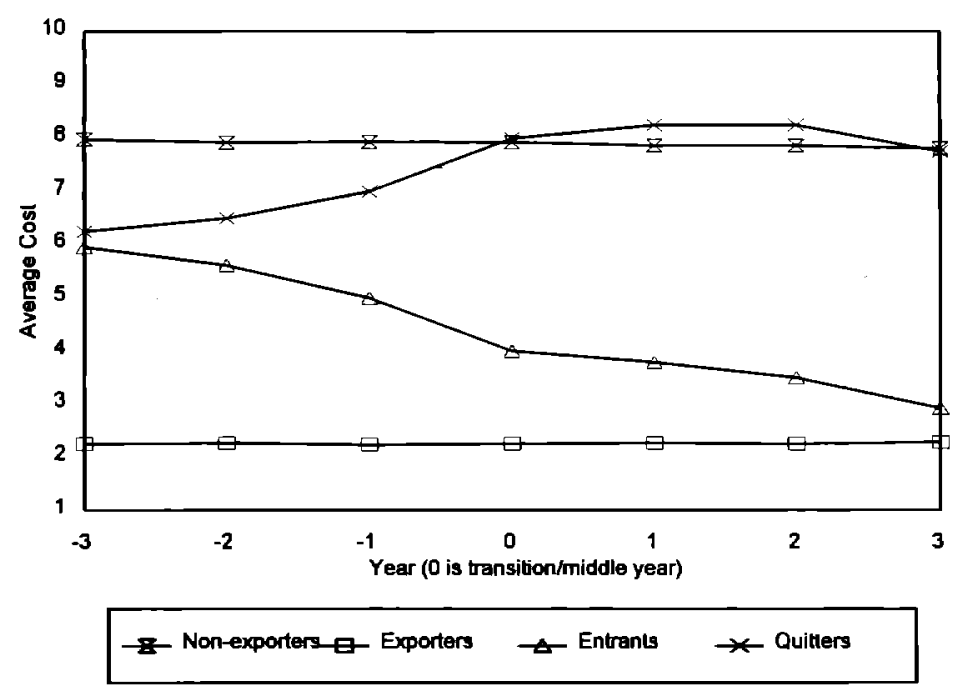

Figure A2.3: Simulated Path of Costs Learning Model III

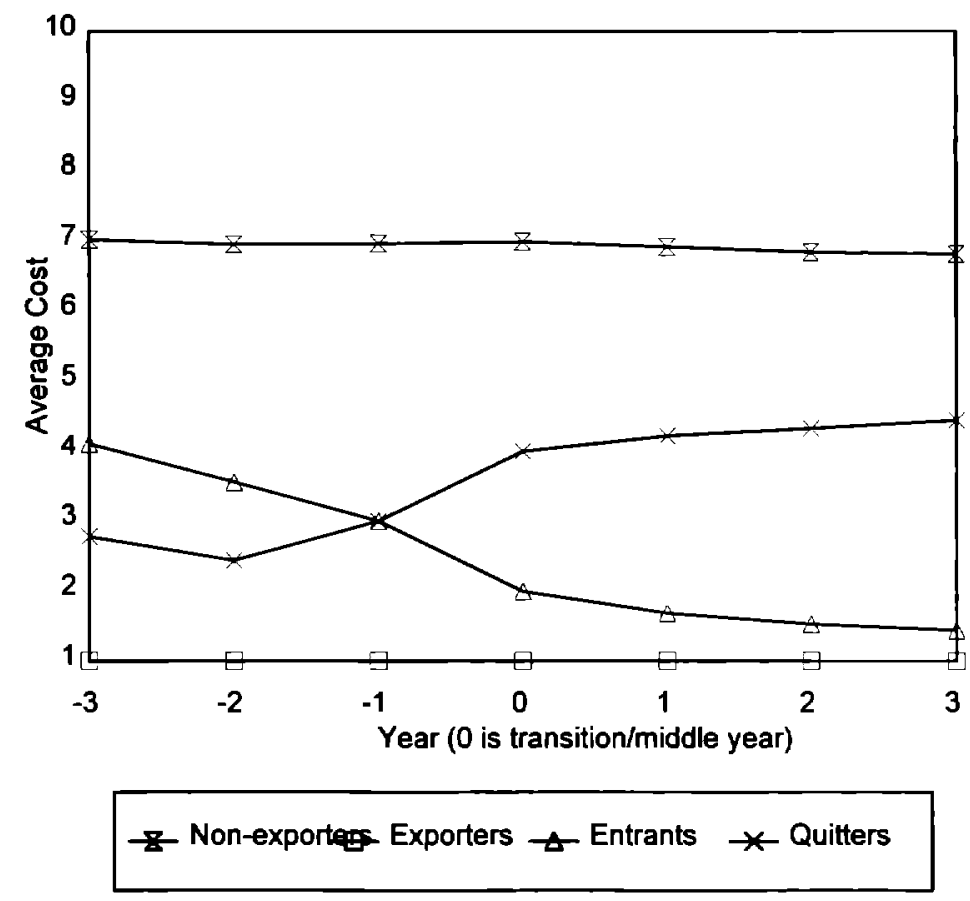


Table A3: Simulation Results

\begin{tabular}{|c|c|c|c|c|}
\hline Model & $\begin{array}{l}\text { Entry } \\
\text { Trigger } \\
\mathrm{C}_{\mathrm{L}}\end{array}$ & $\begin{array}{l}\text { Exit } \\
\text { Trigger } \\
\mathrm{C}_{\mathrm{U}}\end{array}$ & $\begin{array}{l}\text { Entrants'Average } \\
\text { Change in Costs } \\
3 \text { years after }\end{array}$ & $\begin{array}{l}\text { Ratio of Entrants' } \\
\text { to Non-exportes' } \\
\text { Costs } \\
3 \text { years after }\end{array}$ \\
\hline No Learning & 2 & 4 & $4 \%$ & $31 \%$ \\
\hline Learning I & 3 & 6 & $-16 \%$ & $35 \%$ \\
\hline Learning II & 4 & 8 & $-27 \%$ & $38 \%$ \\
\hline Learning III & 2 & 4 & $-28 \%$ & $21 \%$ \\
\hline
\end{tabular}

Because the incentives to export increase when learning occurs, the trigger points shift upwards. That is, it pays to enter at a higher average cost level in anticipation of lower cost due to learning-byexporting and, similarly, it pays to remain an exporters even at higher cost levels. This property of the model implies that the cross-sectional distribution of costs for exporters shifts to the right when learningby-exporting occurs. This may well result in higher expected costs for exporting plants when learning effects are present. Put differently, less-efficient firms tend to enter the export market and remain exporters for longer periods of time when learning effects prevail .

Figure 2.2A provides such an example. In this case, the entry trigger is $\mathrm{c}_{\mathrm{L}}=4$ and the exit trigger is $c_{U}=8$. After three years in the export market the average costs is 2.93 while in the no-learning model it equals 2.08 . Hence, even though costs decline by 27 percent after 3 years exporting, the average costs of exporters relative to the average cost of non-exporters is higher when learning-by-exporting is present. ${ }^{39}$

The message of this example is simply that drawing conslusions about the presence of learning effects across industries from comparisons of entrants' cost levels vis-á-vis the costs of non-exporters

39 Note also that the average costs of non-exporters is higher when learning occurs. 
may be misleading. Hence, cross-industry comparisons of the productivity gap between exporters and non-exporters tell us nothing about the relative strength of learning effects in different industries. Put differently, in order to discriminate between explanations for the export-productivity relationship, one has to examine the dynamic trajectory of costs; a single cross-section will not do. 
APPENDIX II: Data Preparation

\section{A. The Panel Data Sets}

The Colombian data were obtained from the Departamento Administrativo Nacional de Estadistica for the period 1981-1991. They provide annual information on the inputs, outputs, exports, and characteristics of all plants with at least 10 workers. Similar annual survey data were obtained from Morocco's Ministry of Commerce and Industry for the period 1984-1990 and from Mexico's Instituto Nacional de Estadistica Geografia e Informacion for the period 1984-1990, although the Mexican data only cover 3200 of the larger firms. Most of the details on the cleaning and deflating of each of these data bases may be found in the relevant country study chapters of Roberts and Tybout (forthcoming). However, for our analysis of average costs it was necessary to pay special attention to the deflation of exports, so additional measures were taken. Our procedure is summarized below.

\section{B. Construction of Export Unit Values, Price Indices and Average Cost Measures ${ }^{40}$}

Trade data for the the selected sectors for Colombia, Mexico and Morocco were obtained from the United Nations Trade Database. The data are annual total values and quantities for exports and imports for the years 1980-1992. The values are in nominal U.S. dollars, and the data are at the most disaggregated level available within the selected sectors. Disaggregated export unit values were constructed from this data, but could not be used directly in deflating the export volumes reported in the country databases for two reasons. First, because the countries use industrial classification systems that differ from the U.N. system, the classification systems had to be matched. Second, the unit values had to be aggregated up to the level observable in the survey data in each country.

\footnotetext{
${ }^{40}$ This section is reproduced from Roberts, Sullivan, and Tybout (1995), which is based on the same data.
} 
Colombia uses a version of the International Standard Industrial Classification System (ISIC), revision 2. The ISIC was matched to the U.N.'s Standard Industrial Trade Classification (SITC) system at the four digit ISIC level for the industries of interest. Because a detailed listing of products in each four digit ISIC is available (United Nations, 1973), this matching is quite accurate. The Mexico Industry Classification System (Censo Industrial 1975, referred to here as MICS) was matched to the SITC for those four digit industries within the eight industries of interest that actually appear in the Mexico data from 1984-90. This matching is less precise because MICS is only available at a higher level of aggregration than the SITC. The Moroccan Nomenclature of Industrial Activity (NMAE) was matched to the SITC at the very disaggregated six digit level, and the correspondence should therefore be accurate.

After the industry classification systems were matched, the disaggregated export unit values had to be aggregated. Initially, export unit values were aggregated across all SITC commodities contained in a country-specific disaggregated sector (e.g., Colombia four digit ISIC) using as weights actual export value shares from the country data. Some of the export unit values for the SITC commodities showed an unreasonable amount of variation from year to year, however, and this persisted in these initial calculations of an export unit value for an aggregate of these commodities. Because of this, the export unit values were instrumented using import unit values. Three methods of using the import unit values were considered, two of which use information from all countries for which SITC data was obtained. ${ }^{4 !}$ First, a weighted average of import unit values for each commodity was calculated using as weights the actual import value share of each country for each commodity. Second a weighted average import unit value was calculated using the average import value share of each country for each

\footnotetext{
41 In addition to data from Colombia, Mexico and Morocco, Venezuela trade data was used in instrumenting export unit values.
} 
commodity, where the average is taken over the time period for which the data was obtained. Third, for each country, the import unit values from that particular country could be used. Ultimately, the second method of agggregating the import unit values was chosen. The first method using actual shares was not chosen because the import unit values in each year were greatly influenced by commodities entering or exiting the unit value aggregation. The third method using only country specific information was not used because it ignored valuable information on unit values from other countries.

The actual export unit values were regressed on the import unit values calculated using the second method described above, yielding fitted values for each disaggregated SITC commodity. Two methods of aggregating the export unit values for these SITC commodities to the level observable in the country databases were considered. The fitted export unit values could be aggregated using either country-specific actual export value shares or average shares over time from the SITC data. The latter method was chosen, again to eliminate the effect on the unit values of changes in the commodity composition of the sectors.

These instrumented export unit values were in nominal U.S. dollars, and had to be converted to domestic currency units before they could be used for deflating export values reported in the country databases. This required nominal exchange rate indices and a U.S. price index. The U.S. producer price index for consumer goods reported in International Financial Statistics was used to convert to real U.S. dollars. For each country, the annual average nominal exchange rate between the domestic currency and the US dollar reported in various issues of International Financial Statistics was used to convert the export unit values in real U.S. dollars to domestic currency units.

Country specific output price indices were constructed, where possible, using the survey data, or in some cases using other information provided by the respective countries. The Colombia database contains data on both nominal and real total value of production for each plant. The ratio of nominal to 
real value of production is the implicit output price deflator, and this is sector specific at the three digit SIC level. There is some unexplained variation in the three digit price index across plants within an industry, so the mean price index across plants in an industry is used as the output price index. Several plants are deleted from the calculation of the mean price index in particular years because their implicit price index as calculated from the survey data is far from the industry average in a particular year. A broad based output price index for Colombia was constructed as a weighted average of the sectoral output price indices, where the weights are sectoral shares of total real value of production.

For Morocco, the sectoral domestic output price index is taken from various years of the Moroccan Statistical Bulletin. A broad based domestic output price index was constructed as a weighted average of the sectoral output price index, using sectoral shares of total manufacturing production as weights. 


\section{Appendix III: The Likelihood Function}

Our estimator for equations (10) and (11) is closely related to Keane, Moffit, and Runkle's (1988), as well as Sullivan's (1995). To begin, we write these equations in shortened form by collapsing their right-hand-side variables to the vectors $Z_{1}$ and $Z_{2}$, respectively:

$$
\begin{array}{rlrl}
Y_{i t}^{*}=Z_{1 i t} \beta_{1}+\alpha_{1}+\epsilon_{1} & t=J+1, \ldots, T \\
c_{i t}=Z_{2 i t} \beta_{2}+\alpha_{2}+\epsilon_{2} & t=J+1, \ldots, T
\end{array}
$$

where

$$
Y_{i t}=1 \begin{aligned}
& 1 \text { if } Y_{i t}^{*} \geq 0 \\
& 0 \text { if } Y_{i t}^{*}<0
\end{aligned}
$$

(Recall that $J$ periods of lags are needed.) Then the likelihood function, conditioned on $Z_{1}, Z_{2}$, $\alpha_{1}$, and $\alpha_{2}$ may be written as:

$$
\begin{aligned}
L\left(Y, c \mid Z_{1}, Z_{2}, \alpha_{1}, \alpha_{2}, \theta\right) & =\prod_{i=1}^{n} \prod_{i=J+1}^{T}\left[f\left(c_{i r} Y_{i r}=1\right) \operatorname{Pr}\left(Y_{i r}=1\right)\right]^{Y_{i t}}\left[f\left(c_{i r} \mid Y_{i t}=0\right) \operatorname{Pr}\left(Y_{i t}=0\right)\right]^{1-Y_{i t}} \\
& =\prod_{i=1}^{n} \prod_{t=J+1}^{T}\left[f\left(c_{i t} Y_{i t}^{*} \geq 0\right) \operatorname{Pr}\left(Y_{i t}^{*} \geq 0\right)\right]^{Y_{i r}}\left[f\left(c_{i r} \mid Y_{i t}^{*}<0\right) \operatorname{Pr}\left(Y_{i t}<0\right)\right]^{t-Y_{i t}}
\end{aligned}
$$

where $\theta=\left(\beta_{1}, \beta_{2}, \sigma_{\epsilon_{1}}^{2}, \sigma_{\epsilon_{2}}^{2}, \sigma_{\epsilon_{1}, \epsilon_{2}}\right)$. To simplify the conditional density functions, note that:

$$
\begin{aligned}
f\left(c_{i t} \mid Y_{i t}^{*} \geq 0\right) \operatorname{Pr}\left(Y_{i t}^{*} \geq 0\right) & =\int_{0}^{\infty} f\left(c_{i t} Y_{i t}^{*}\right) d Y_{i r}^{*}=\int_{0}^{\infty} f\left(Y_{i r}^{*} \mid c_{i t}\right) f\left(c_{i t}\right) d Y_{i r}^{*} \\
& =f\left(c_{i t}\right) \int_{0}^{\infty} f\left(Y_{i t}^{*} \mid c_{i t}\right) d Y_{i t}^{*}=f\left(c_{i t}\right)\left[1-\int_{-\infty}^{0} f\left(Y_{i t}^{*} \mid c_{i t}\right) d Y_{i t}^{*}\right]=f\left(c_{i t}\right)[1-G(0)]
\end{aligned}
$$


where $G()$ is the cumulative distribution for $Y_{i r}^{*} \mid c_{i r}$. Similarly, $f\left(c_{i t} \mid Y_{i t}^{*} \leq 0\right) \operatorname{Pr}\left(Y_{i t} \leq 0\right)=f\left(c_{i r}\right) G(0)$.

Assuming that $\left(\epsilon_{1 i r}, \epsilon_{2 i r}\right)$ is jointly normal, we have:

$$
Y_{i t}^{*} \mid c_{i t} \sim N\left(Z_{1 i t} \beta_{1}+\alpha_{1 i}+\left(\frac{\sigma_{\epsilon_{1}, \epsilon_{2}}}{\sigma_{\epsilon_{2}}^{2}}\right)\left(c_{i i t}-Z_{2 i t} \beta_{2}-\alpha_{2 i}\right), \quad \sigma_{\epsilon_{1}}^{2}-\frac{\sigma_{\epsilon_{1}, \epsilon_{2}}}{\sigma_{\epsilon_{2}}^{2}}\right),
$$

so the conditional likelihood function can be written as

$$
L=\prod_{i=1}^{n} \prod_{t=J+1}^{T} f\left(c_{i t}\right)[1-G(0)]^{Y_{t \prime}} G(0)^{1-Y_{t i}},
$$

where

$$
\begin{aligned}
& G(0)=\Phi\left(-\left[Z_{1 i t} \beta_{1}+\alpha_{1 i}+\left(\frac{\sigma_{\epsilon_{1}, \epsilon_{2}}}{\sigma_{\epsilon_{2}}^{2}}\right)\left(c_{i t}-Z_{2 i t} \beta_{2}-\alpha_{2 i}\right)\right]\left[\sigma_{\epsilon_{1}}^{2}-\frac{\sigma_{\epsilon_{1}, \epsilon_{2}}}{\sigma_{\epsilon_{2}}^{2}}\right]^{-1 / 2}\right) \\
& f\left(c_{i j}\right)=\Phi\left(\frac{c_{i t}-Z_{2 i t} \beta_{2}-\alpha_{2 i}}{\sigma_{\epsilon_{2}}}\right)
\end{aligned}
$$

and $\Phi()$ and $\phi()$ are the standard normal distribution and density functions, respectively.

There are two complications involved in estimation. The first is that the error components $\alpha_{2}$ and $\alpha_{1}$, are unobserved, so they cannot be conditioned upon in estimation. The second derives

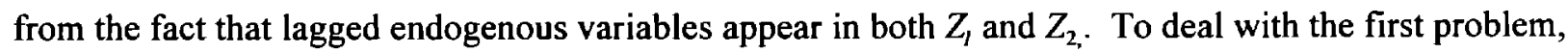
we assume a bivariate normal distribution for the error components, $h\left(\alpha_{1}, \alpha_{2}\right)$, and integrate them out. $^{42}$ To deal with the second problem, we follow Heckman's (1981) suggestion of adding equations to

${ }^{42}$ More specifically, we first express the two components as linear combinations of two orthogonal random variables using a Cholesky decomposition. Then we integrate out these orthogonal random variables using bivariate Gaussian quadrature. See Sullivan (1995) for details. 
the system that represent the dependence of $\left(Y_{i 1}, Y_{i 2}, \ldots, Y_{i}\right)$ on $\alpha_{1 i}$ and the dependence of

$$
\begin{aligned}
\left(c_{i t}, c_{i 2}, \ldots, c_{i j}\right) & \text { on } \alpha_{2 i}: \\
Y_{i t}^{*} & =Z_{1 i t}^{0} \Psi_{1}+\rho_{1} \alpha_{1}+\xi_{1 i t} \quad t=1, \ldots, J \\
c_{i t} & =Z_{2 i t}^{0} \Psi_{2}+\rho_{2} \alpha_{2}+\xi_{2 i t} \quad t=1, \ldots, J
\end{aligned}
$$

Here $Z_{1 i t}^{0} \subset Z_{1 i t}$ is the vector of strictly exogenous determinants of $Y_{i t}^{*}, \quad Z_{2 i t}^{0} \subset Z_{2 i t}$ is the vector of strictly exogenous determinants of $c_{i t}$, and $\left(\xi_{1 i t}, \xi_{2 i t}\right)$ is a serially uncorrelated bivariate normal random vector. The likelihood function conditioned only on observable data becomes:

$$
L=\int_{-\infty}^{\infty} \int_{-\infty}^{\infty} \prod_{i=1}^{N}\left(\prod_{i=1}^{J} \tilde{f}\left(c_{i t}\right)[1-\tilde{G}(0)]^{Y_{i \prime}} \bar{G}(0)^{1-Y_{u}}\right)\left(\prod_{i=J+1}^{T} f\left(c_{i t}\right)[1-G(0)]^{Y_{u t}} G(0)^{1-Y_{t i}}\right) h\left(\alpha_{1}, \alpha_{2}\right) d \alpha_{1} d \alpha_{2}
$$

where

$$
\begin{aligned}
& \tilde{G}(0)=\Phi\left(-\left[z_{1 i t}^{0} \Psi_{1}+\rho_{1} \alpha_{1 i}+\left(\frac{\sigma_{\xi_{1}, \xi_{2}}}{\sigma_{\xi_{2}}^{2}}\right)\left(c_{i t}-Z_{2 i t}^{0} \Psi_{2}-\rho_{2} \alpha_{2 i}\right)\right]\left[\sigma_{\xi_{1}}^{2}-\frac{\sigma_{\xi_{1}, \xi_{2}}}{\sigma_{\xi_{2}}^{2}}\right]^{-1 / 2}\right) \\
& \tilde{f}\left(c_{i t}\right)=\Phi\left(\frac{c_{i t}-z_{2 i t}^{0} \Psi_{2}-\rho_{2} \alpha_{2 i}}{\sigma_{\xi_{2}}}\right)
\end{aligned}
$$

The nuisance parameters associated with the $J$ presample years of data are not reported in Table 6 . 